\title{
Dimensionless Analysis of Segmented Constrained Layer Damping Treatments with Modal Strain Energy Method
}

\author{
Shitao Tian, ${ }^{1,2}$ Zhenbang Xu, ${ }^{1}$ Qingwen Wu, ${ }^{1}$ and Chao Qin ${ }^{1}$ \\ ${ }^{1}$ Innovation Lab of Space Robot System, Changchun Institute of Optics, Fine Mechanics and Physics, Chinese Academy of Sciences, \\ No. 3888 Dong Nanhu Road, Changchun 130033, China \\ ${ }^{2}$ University of Chinese Academy of Sciences, No. 19A Yuquan Road, Beijing 100049, China
}

Correspondence should be addressed to Zhenbang Xu; xuzhenbang@gmail.com

Received 17 September 2015; Accepted 26 October 2015

Academic Editor: Sergio De Rosa

Copyright (c) 2016 Shitao Tian et al. This is an open access article distributed under the Creative Commons Attribution License, which permits unrestricted use, distribution, and reproduction in any medium, provided the original work is properly cited.

\begin{abstract}
Constrained layer damping treatments promise to be an effective method to control vibration in flexible structures. Cutting both the constraining layer and the viscoelastic layer, which leads to segmentation, increases the damping efficiency. However, this approach is not always effective. A parametric study was carried out using modal strain energy method to explore interaction between segmentation and design parameters, including geometry parameters and material properties. A finite element model capable of handling treatments with extremely thin viscoelastic layer was developed based on interlaminar continuous shear stress theories. Using the developed method, influence of placing cuts and change in design parameters on the shear strain field inside the viscoelastic layer was analyzed, since most design parameters act on the damping efficiency through their influence on the shear strain field. Furthermore, optimal cut arrangements were obtained by adopting a genetic algorithm. Subject to a weight limitation, symmetric and asymmetric configurations were compared. It was shown that symmetric configurations always presented higher damping. Segmentation was found to be suitable for treatments with relatively thin viscoelastic layer. Provided that optimal viscoelastic layer thickness was selected, placing cuts would only be applicable to treatments with low shear strain level inside the viscoelastic layer.
\end{abstract}

\section{Introduction}

Real structures are made up of components possessing finite levels of rigidity and mass. Vibration is inevitably provoked when force is transmitted through a structure, eventually leading to failure due to fatigue. Constrained layer damping (CLD) treatments are usually applied to structures to improve their dynamic behavior [1, 2]. This approach allows for enhanced damping capabilities over a wide frequency range. As a result, it is widely used in various engineering structures such as ships, trains, automobiles, and commercial airplanes [3-5]. A majority of the current work pertaining to CLD treatments for structures is focused on optimizing CLD configurations and related parameters to maximize structural damping rate. Moreover, initiating cuts into the treatment, adopting active CLD treatments, or partially covering base structures with CLD treatments could further increase damping capacity $[6,7]$.
A key issue in design and optimization of CLD treatments is related to modeling of the treated structure and quantitative assessment of system damping. Kinematics and theories specific to multilayered composite structures can be classified as equivalent single layer (ESL) theories and layerwise (LW) theories, based on the through-the-thickness description of displacement and stress fields [8]. The number of unknown variables in ESL theories is independent of the number of layers. Classical laminated plate theory (CLPT) [9], firstorder shear deformation theory (FSDT) [10], and highorder shear deformation theory (HSDT) [11] are all easy-toimplement ESL theories.

A majority of composite structures contain soft cores and the physical/mechanical properties in the thickness direction are discontinuous. Thus, CLPT theories and FSDT theories are of limited value in the analysis of composite structures for poor descriptions of the high-shear deformation inside the soft cores. Alternatively, LW theories can guarantee 
a high degree of accuracy at the expense of computational complexity. The number of unknown variables in LW theories increases with the number of layers and zigzag effects are considered intrinsically $[12,13]$. The zigzag effect of displacement and the interlaminar continuity of shear stress in the thickness direction are crucial for accurate description of the shear deformation [14-17]. High-order theories including the zigzag effect and the interlaminar continuity of shear stress accurately predict the shear stress as well $[18,19]$.

CLD treatments are characterized by sandwiching a viscoelastic core between two stiff face layers, that is, the base structure layer and the constraining layer. Kerwin et al. $[20,21]$ provided a simple analytical method based on zigzag theories for analyzing three-layered beams. This method is known as the RKU equation. However, the method is only applicable to simply supported beams. Mead and Markus [22] derived a sixth-order differential equation of motion in terms of transverse displacement for sandwich beams. Rao [23] solved these equations exactly for different boundary conditions. The RKU equation is a typical zigzag model, which describes piecewise continuous displacement fields. A majority of the subsequent models developed for analysis of three-layered CLD treated structures are based on Kerwin's hypotheses, which does not take the interlaminar continuity of shear stress into consideration [24-30]. A spectral finite element is developed for linear viscoelastic laminates and it focuses on an exact description of the through-thickness deformation [31-34]. Based on this, Zigzag theories can be classified into two categories: interlaminar discontinuous shear stress (IDSS) zigzag theories and interlaminar continuous shear stress (ICSS) zigzag theories.

$\mathrm{Hu}$ et al. [35] compared several theories used for the modeling of sandwich structures to address the applicability and validity of these theories. It was shown that ICSS zigzag theories could be used for modeling all types of three-layered structures whereas IDSS zigzag theories were inadequate for modeling sandwich structures with thick or rigid viscoelastic layers. According to Huang et al. [7], an extremely thin viscoelastic layer would cause difficulty in the solution for models based on Kerwin's hypotheses. Lesieutre and Lee [30] presented a finite element model for beams with segmented active constrained layers based on IDSS theories. In this study, the interlaminar continuity of shear stress was further included to model segmented three-layered beams.

A layered shell/solid/shell model using classical finite elements available in most commercial software is often used to model structures with CLD treatments. Plouin and Balmes [36] demonstrated the validity of the shell/solid/shell model by correlation with experimental results and Moreira and Rodrigues [37] further assessed the performance of the shell/solid/shell model. Johnson and Kienholz [38] proposed the modal strain energy (MSE) method to calculate loss factor for each mode of the structure using the shell/solid/shell model. The modal strain energy method has been proven to be an accurate and flexible tool for quantitatively determining damping of structures. Zhang and Chen [39] proposed an iterative method which took the frequency dependent properties of viscoelastic materials into consideration. Koruk and Sanliturk [40] assessed the performance of the MSE method and concluded that accuracy of the MSE method was strongly dependent on mode shapes of the base structures.

Initiating cuts into the damping treatment could significantly improve structural damping rate. However, such an approach has been found not to be effective for all cases. Efficiency of segmenting a constrained layer damping treatment relies on the fact that a high-shear region is created in the viscoelastic layer. Such phenomenon is called edge effect. Plunkett and Lee [41] invented the concept of segmenting the constraining layer and derived an expression for optimum distance of equidistant cuts arrangements assuming pure extension of the treated structure. Trompette and Fatemi [42] determined an optimal distribution of cuts for maximum damping of a flexural sandwich beam with selected parameters. Al-Ajmi and Bourisli [43] used a genetic algorithm to investigate the relationship of the viscoelastic layer thickness, the constraining layer thickness, and the number of cuts. It was found that the optimum number of cuts decreased with increasing thickness of the viscoelastic layer. Lepoittevin and Kress [44] analyzed the mechanism of cuts and developed an optimization algorithm to optimize distribution of cuts for simultaneously damping multiple modes [44]. Hujare et al. [45] conducted an experimental analysis of the effect of segmented CLD treatments based on the work of Lepoittevin and Kress [44]. Kadam and Hujare [46] carried out a literature review related to methods on segmented CLD treatments.

Segmentation enhances damping capacity of active constrained layer damping treatments. Kapadia and Kawiecki [47] demonstrated the effect of active constrained layer segmentation on the damping efficiency in flexible beams. Experimental results demonstrated improved damping in the beams due to active constraining layer segmentation. Improvement in damping at lower natural frequencies was found to be significantly higher in comparison to high natural frequencies. Trindade et al. [48] analyzed the performance of segmented hybrid active-passive damping of a cantilever beam as compared to passive one for some parametric variations such as viscoelastic layer thickness and treatment length. Liu and Wang [49] investigated the effect of multiple active and passive constraining section distributions and the effect of mode shapes for host structure on the treatment performance. Segmentation is not always effective in increasing structural damping efficiency. Kristensen et al. [50] found that creating a cut in the center of a simply supported beam results in a decrease of the loss factors.

Thickness and material properties of each layer have an obvious influence on the effectiveness of segmentation. A majority of the research reported in literature on segmented CLD treatments emphasizes finding the best cut distribution for treatments with specific parameters [42-45]. However, the applicability of segmentation in these cases has not been taken into account. The effectiveness of segmentation is an important issue for practical design considerations while applying segmentation to enhance damping capabilities of CLD treatments. Initiating a cut into the treatment would reshape the shear strain field inside the viscoelastic layer. The shear strain field and the volume of the viscoelastic material are directly responsible for energy dissipation in the viscoelastic layer and consequently for the damping 
efficiency. Thickness variation of the viscoelastic layer does alter the volume of viscoelastic material and the shear strain field. Sher and Moreira [51] studied the relationship between the viscoelastic layer thickness and the damping efficiency. It has been shown that the shape of the damping efficiency versus viscoelastic layer thickness curve is different according to the shear strain level inside the viscoelastic layer. Moreover, design parameters have an effect on the shape of the efficiency curve. For this reason, damping efficiency curves for CLD treatments with different parameter values are generated to predict the shear strain level. Based on these curves, relationship between the effectiveness of segmentation and the shear strain field is studied.

In the present study, a finite element model capable of handling treatments with extremely thin viscoelastic layer was developed on the basis of interlaminar continuous shear stress theories. Interaction between the effectiveness of cuts and design parameters is explored. Dimensionless parameters are utilized to allow generalization of the results and allow universal applicability of the results. Section 2 presents the finite element model for segmented CLD treatments based on the ICSS theory and briefly introduces the MSE method. Section 3 compares the finite element model with that based on the IDSS theory and validates the model by comparison with the shell/solid/shell model. Section 4 explores the relationship between the effectiveness of segmentation and the shear strain field inside the viscoelastic layer. The influence of an arbitrarily placed cut on the shear strain field is discussed. The effect of other design parameters on the shear strain field is analyzed. A genetic algorithm is then utilized to determine the best distribution of cuts. Additionally, symmetric and asymmetric configurations are compared (a symmetric configuration implies a constraining layer with the same thickness as the base beam). Section 5 discusses application of segmentation to CLD treatments.

\section{Finite Element Development}

2.1. CLD Configuration and Kinematic Assumptions. A cantilever beam with segmented CLD treatments is considered here. General configuration of the treated beam is depicted in Figure 1. The three-layered beam consists of three components, namely, the base beam, viscoelastic layer, and constraining layer, denoted with subscripts $b, v$, and $c$, respectively. All points are denoted using independent coordinates $x$ and $z$, with the origin of the coordinate system located at the center of the left end of the base beam. Length and thickness of the beam are denoted by $L$ and $h$, respectively.

The model is based on the following assumptions.

(1) All displacements are small compared to the structural dimensions. Linear theories of elasticity and viscoelasticity are applicable. All layers are perfectly bound and no slip occurs between layers.

(2) The Bernoulli-Euler bending assumptions are valid for the base beam. Transverse normal stress in the base beam is neglected.

(3) The viscoelastic layer carries transverse shear. Transverse normal stress and longitudinal normal stress are

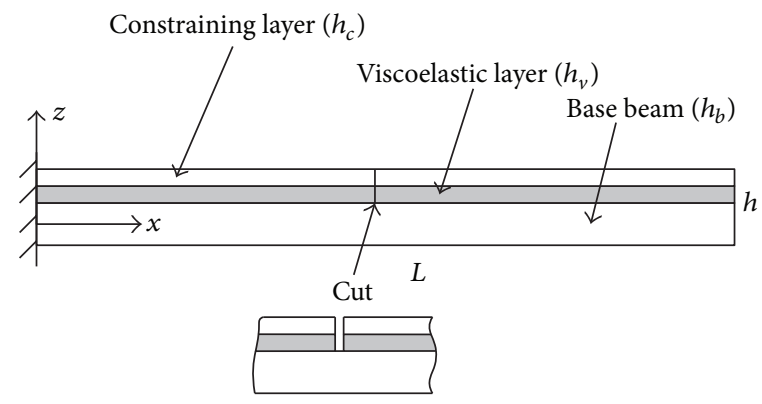

Figure 1: Cantilever beam with segmented CLD treatments.

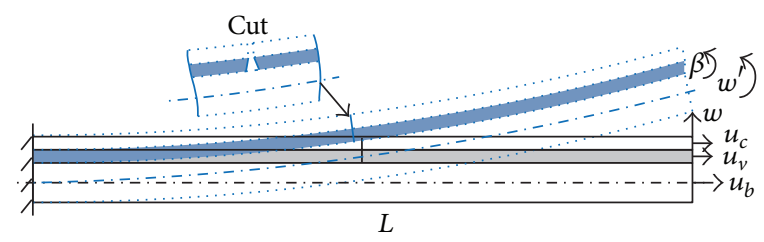

FIGURE 2: Deformation of the beam with segmented CLD treatments.

neglected. Shear modulus is frequency dependent and complex.

(4) All points in the cross section undergo the same transverse deflection.

(5) The constraining layer is elastic. The transverse shear stress is continuous at the interface of the viscoelastic layer and the constraining layer and vanishes at the top surface of the constraining layer.

2.2. Displacement Fields. The deformation of the treated beam is illustrated in Figure 2. Longitudinal and transverse displacements are denoted by $u$ and $w$, respectively. The superscript ' denotes the partial derivative with respect to $x$ and $w^{\prime}$ denotes the transverse rotation. The shear angle in the viscoelastic layer is denoted by $\beta$.

Lesieutre and Lee [30] developed a finite element model for beams having segmented active constrained layers based on the IDSS zigzag theory. The displacement field is given by the following equation:

$$
\begin{aligned}
& u_{b}(x, z, t)=u_{0}(x, t)-z w^{\prime}(x, t), \\
& u_{v}(x, z, t)=u_{0}(x, t)-z w^{\prime}(x, t)-\left(z-\frac{h_{b}}{2}\right) \beta(x, t), \\
& u_{c}(x, z, t)=u_{0}(x, t)-z w^{\prime}(x, t)-h_{v} \beta(x, t), \\
& w(x, z, t)=w(x, t),
\end{aligned}
$$

where $u_{0}$ denotes the longitudinal displacement at the reference axis and $\beta$ denotes the shear angle in the viscoelastic layer. The displacement of each layer is given in terms of the above four variables, namely, $u_{0}, w, w^{\prime}$, and $\beta$. The constraining layer can be segmented simply by not enforcing element-to-element continuity of $\beta$. Models based on IDSS theories present erroneous results when the viscoelastic layer 
thickness approaches zero. Therefore, the displacement field is refined by including continuity conditions and free surface conditions of transverse shear stress. If segmentation is realized by discontinuity of $\beta$, the continuity condition and the free surface condition of transverse shear stress cannot be satisfied simultaneously at cut's location. Thus, the transverse shear stress continuity condition between the base beam and viscoelastic layer was not taken into account. It was assumed that transverse shear stress was just continuous at the interface between the viscoelastic layer and constraining layer. In addition, shear stress was assumed to vanish at the top surface of the constraining layer. Moreover, the displacement continuity condition needs to be considered. Hence, the second-order displacement field was employed in the constraining layer to meet the above three conditions. The refined displacement field is given by

$$
\begin{aligned}
u_{b}(x, z, t)= & u_{0}(x, t)-z w^{\prime}(x, t), \\
u_{v}(x, z, t)= & u_{0}(x, t)-z w^{\prime}(x, t)-\left(z-\frac{h_{b}}{2}\right) \beta(x, t), \\
u_{c}(x, z, t)= & u_{0}(x, t)-z w^{\prime}(x, t) \\
& +\left(k_{2} z^{2}+k_{1} z+k_{0}\right) \beta(x, t), \\
w(x, z, t)= & w(x, t),
\end{aligned}
$$

where $k_{2}, k_{1}$, and $k_{0}$ are three unknown parameters.

Longitudinal normal and transverse shear strains at any point in the treated beam can be found using the following definition:

$$
\begin{aligned}
\varepsilon_{x x} & =\frac{\partial u}{\partial x}, \\
\varepsilon_{x z} & =\frac{\partial u}{\partial z}+\frac{\partial w}{\partial x} .
\end{aligned}
$$

Based on the above three conditions, three equations can be derived, which are stated as follows:

$$
\begin{aligned}
& \left.G_{v}\left(\frac{\partial u_{v}}{\partial z}+\frac{\partial w}{\partial x}\right)\right|_{z=h_{b} / 2+h_{v}} \\
& \quad=\left.G_{c}\left(\frac{\partial u_{c}}{\partial z}+\frac{\partial w}{\partial x}\right)\right|_{z=h_{b} / 2+h_{v}}, \\
& \left.G_{c}\left(\frac{\partial u_{c}}{\partial z}+\frac{\partial w}{\partial x}\right)\right|_{z=h-h_{b} / 2}=0, \\
& \left.u_{v}(x, z, t)\right|_{z=h_{b} / 2+h_{v}}=\left.u_{c}(x, z, t)\right|_{z=h_{b} / 2+h_{v}} .
\end{aligned}
$$

Young's modulus and shear modulus are denoted with $E$ and $G$, respectively. $G_{v}$ is the shear storage modulus.

Solving the above equations, the three unknown parameters are obtained as follows:

$$
\begin{aligned}
& k_{2}=\frac{G_{v}}{2 G_{c} h_{c}}, \\
& k_{1}=-\frac{G_{v}}{G_{c} h_{c}\left(h-h_{b} / 2\right)}, \\
& k_{0}=-h_{v}-k_{2}\left(h_{v}+\frac{h_{b}}{2}\right)^{2}-k_{1}\left(h_{v}+\frac{h_{b}}{2}\right) .
\end{aligned}
$$

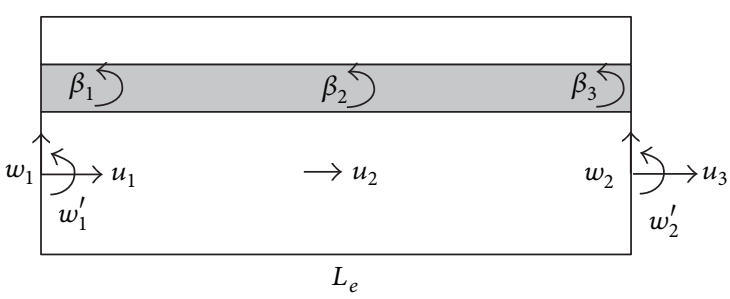

FIGURE 3: Nodal degrees of freedom for a finite element.

2.3. Shape Functions. Displacement at any point is denoted using nodal displacements with the help of shape functions. Displacement at a point in the treated beam is represented using four variables, namely, longitudinal displacement at the reference axis $u_{0}$, transverse displacement $w$, transverse rotation $w^{\prime}$, and shear angle in the viscoelastic layer $\beta$. Nodal degrees of a finite element to be developed are depicted in Figure 3. Length of the element is $L_{e}$.

Transverse displacement $w$ was interpolated using a cubic polynomial in $x$ and is given by

$$
\begin{aligned}
& w(x, t)=\left[N_{w}\right]\{w\}, \\
& {\left[N_{w}\right]=\left[1-3\left(\frac{x}{L_{e}}\right)^{2}\right.} \\
& +2\left(\frac{x}{L_{e}}\right)^{3},\left(\left(\frac{x}{L_{e}}\right)-2\left(\frac{x}{L_{e}}\right)^{2}+\left(\frac{x}{L_{e}}\right)^{3}\right) \\
& \left.\cdot L_{e}, 3\left(\frac{x}{L_{e}}\right)^{2}-2\left(\frac{x}{L_{e}}\right)^{3},\left(-\left(\frac{x}{L_{e}}\right)^{2}+\left(\frac{x}{L_{e}}\right)^{3}\right) L_{e}\right] \text {, } \\
& \{w\}=\left[w_{1}(x, t), w_{1}^{\prime}(x, t), w_{2}(x, t), w_{2}^{\prime}(x, t)\right]^{T} .
\end{aligned}
$$

Longitudinal displacement at the reference axis $u_{0}$ and shear angle in the viscoelastic layer $\beta$ were interpolated consistent with $w^{\prime}$ using a quadratic polynomial in $x$, using an internal node. Thus, the element will not shear lock:

$$
\begin{aligned}
& u_{0}(x, t)=\left[N_{u}\right]\{u\}, \\
& {\left[N_{u}\right]=\left[1-3\left(\frac{x}{L_{e}}\right)+2\left(\frac{x}{L_{e}}\right)^{2}, 4\left(\frac{x}{L_{e}}\right)-4\left(\frac{x}{L_{e}}\right)^{2},\right.} \\
& \left.\quad-\left(\frac{x}{L_{e}}\right)+2\left(\frac{x}{L_{e}}\right)^{2}\right], \\
& \{u\}=\left[u_{1}(x, t), u_{2}(x, t), u_{3}(x, t)\right]^{T}, \\
& \beta(x, t)=\left[N_{u}\right]\{\beta\}, \\
& \{\beta\}=\left[\beta_{1}(x, t), \beta_{2}(x, t), \beta_{3}(x, t)\right]^{T} .
\end{aligned}
$$

The local nodal displacement vector for the element is given by the following:

$$
\left\{q_{e}\right\}=\left[u_{1}, u_{2}, u_{3}, w_{1}, w_{1}^{\prime}, w_{2}, w_{2}^{\prime}, \beta_{1}, \beta_{2}, \beta_{3}\right]^{T} .
$$


2.4. Stiffness and Mass Matrices. Associated stiffness and mass matrices were developed using the energy expression. The potential energy is associated with the stiffness matrix and the kinetic energy is associated with the mass matrix.

The potential energy stored in a deformed element of width $b$ and length $L_{e}$ is given by

$$
\begin{aligned}
U & =U_{E}+U_{G}, \\
U_{E} & =\frac{1}{2} b \int_{0}^{L_{e}}\left(\int_{-h_{b} / 2}^{h_{b} / 2} E_{b}\left(\frac{\partial u_{b}}{\partial x}\right)^{2} d z\right. \\
& \left.+\int_{h_{b} / 2+h_{v}}^{h-h_{b} / 2} E_{c}\left(\frac{\partial u_{c}}{\partial x}\right)^{2} d z\right) d x=\frac{1}{2}\left\{q_{e}\right\}^{T}\left[K_{E}^{(e)}\right] \\
& \cdot\left\{q_{e}\right\}, \\
U_{G} & =\frac{1}{2} b \int_{0}^{L_{e}}\left(\int_{h_{b} / 2}^{h_{b} / 2+h_{v}} G_{v}\left(\frac{\partial u_{v}}{\partial z}+\frac{\partial w}{\partial x}\right)^{2} d z\right. \\
& \left.+\int_{h_{b} / 2+h_{v}}^{h-h_{b} / 2} G_{c}\left(\frac{\partial u_{c}}{\partial z}+\frac{\partial w}{\partial x}\right)^{2} d z\right) d x \\
& =\frac{1}{2}\left\{q_{e}\right\}^{T}\left[K_{G}^{(e)}\right]\left\{q_{e}\right\},
\end{aligned}
$$

where $U_{E}$ is the potential energy due to extension and bending and $U_{G}$ is the potential energy due to shear strain. The element stiffness matrix is given by

$$
\left[K^{(e)}\right]=\left[K_{E}^{(e)}\right]+\left[K_{G}^{(e)}\right] .
$$

The kinetic energy of a moving element of width $b$ and length $L_{e}$ is given by

$$
\begin{aligned}
T & =T_{w}+T_{u}, \\
T_{w} & =\frac{1}{2} b \int_{0}^{L_{e}}\left(\rho_{b} h_{b}+\rho_{v} h_{v}+\rho_{c} h_{c}\right)\left(\frac{\partial w}{\partial t}\right)^{2} d x \\
& =\frac{1}{2}\left\{\dot{q}_{e}\right\}^{T}\left[M_{w}^{(e)}\right]\left\{\dot{q}_{e}\right\}, \\
T_{u} & =\frac{1}{2} b \int_{0}^{L_{e}}\left(\int_{-h_{b} / 2}^{h_{b} / 2} \rho_{b}\left(\frac{\partial u_{b}}{\partial t}\right)^{2} d z\right. \\
& +\int_{h_{b} / 2}^{h_{b} / 2+h_{v}} \rho_{v}\left(\frac{\partial u_{v}}{\partial t}\right)^{2} d z \\
& \left.+\int_{h_{b} / 2+h_{v}}^{h-h_{b} / 2} \rho_{c}\left(\frac{\partial u_{c}}{\partial t}\right)^{2} d z\right) d x=\frac{1}{2}\left\{\dot{q}_{e}\right\}^{T} \\
& \cdot\left[M_{u}^{(e)}\right]\left\{\dot{q}_{e}\right\},
\end{aligned}
$$

where $T_{w}$ is the kinetic energy associated with transverse motion and $T_{u}$ is the kinetic energy associated with longitudinal motion. Material density is denoted with $\rho$. The element mass matrix is given by

$$
\left[M^{(e)}\right]=\left[M_{w}^{(e)}\right]+\left[M_{u}^{(e)}\right] .
$$

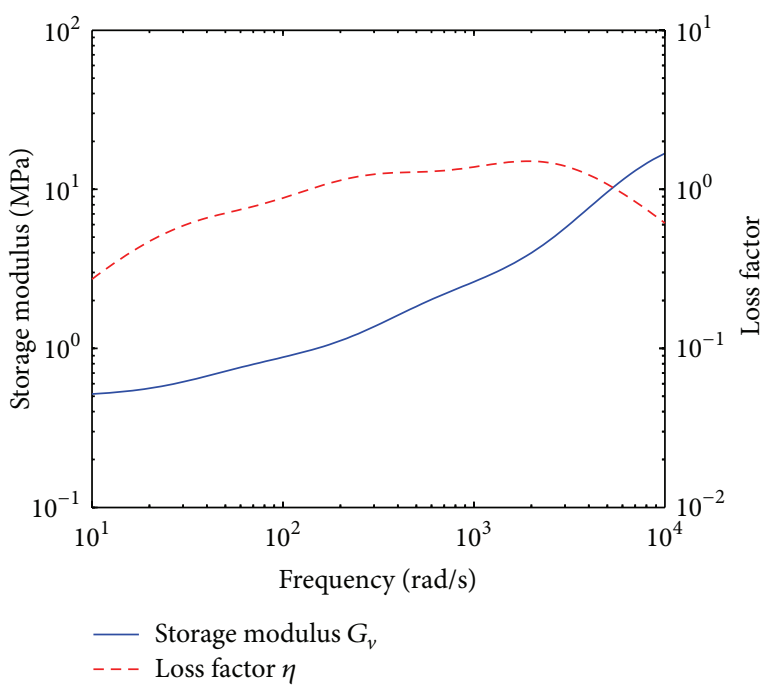

FIGURE 4: Frequency dependent properties of 3M ISD112 at $0^{\circ} \mathrm{C}$.

Detailed expressions for the element stiffness and mass matrices are given in the appendix.

For the cantilever beam with segmented CLD treatments, through standard FEM assembling procedures and with appropriate boundary conditions, the differential equation for free vibrations can be expressed as

$$
[M]\{\ddot{q}\}+[K]\{q\}=0,
$$

where $[M],[K],\{\ddot{q}\}$, and $\{q\}$ are the global mass matrix, the global stiffness matrix, the global acceleration vector, and the global displacement vector, respectively. The global stiffness matrix is derived using the shear storage modulus of the viscoelastic material.

2.5. MSE Method. Viscoelastic material representation is an important issue when dealing with CLD treatments. The complex modulus approach is adopted here to represent viscoelastic materials, whose properties are frequency and temperature dependent:

$$
G(\omega)=G_{v}(\omega)(1+i \eta(\omega)),
$$

where $G_{v}$ and $\eta$ are shear storage modulus and loss factor of viscoelastic materials. The viscoelastic material used in this study is 3M-ISD112. Its material properties are provided in the standard reduced temperature format in [52]. In Figure 4 are shown the shear storage modulus and loss factor of the viscoelastic material at the ambient temperature $\left(0^{\circ} \mathrm{C}\right)$. These parameters are extracted from the nomogram presented in [52].

The base beam and constraining layer are made of aluminum. Material parameters are listed in Table 1. Material damping of the base beam and constraining layer is neglected. Material density primarily affects the natural frequencies of the treated beam and has no direct effect on the damping efficiency of the CLD treatment. 
TABLE 1: Material properties.

\begin{tabular}{lcccc}
\hline Material type & $\begin{array}{c}\text { Young's } \\
\text { modulus } \\
(\mathrm{MPa})\end{array}$ & Poisson ratio & $\begin{array}{c}\text { Density } \\
\left(\mathrm{kg} / \mathrm{m}^{3}\right)\end{array}$ & Loss factor \\
\hline Aluminum & 68000 & 0.33 & 2800 & 0 \\
ISD112 & - & 0.49 & 1200 & - \\
\hline
\end{tabular}

The differential equation for free vibrations of the treated beam is given by

$$
[M]\{\ddot{q}\}+\left([K]+i\left[K_{v}\right]\right)\{q\}=0,
$$

where $\left[K_{v}\right]$ is the loss stiffness matrix associated with the viscoelastic layer. The stiffness matrix is complex and the eigenvalue problem can be written as

$$
\left([K]+i\left[K_{v}\right]\right)\left\{\Phi_{r}^{*}\right\}=\lambda_{r}^{* 2}[M]\left\{\Phi_{r}^{*}\right\},
$$

where $\left[\lambda_{r}^{*}\right]$ and $\left[\Phi_{r}^{*}\right]$ are the $r$ th complex eigenvalue and eigenvector, respectively. The complex eigenvalue can be written as

$$
\lambda_{r}^{* 2}=\lambda_{r}^{2}\left(1+i \eta_{r}\right),
$$

where $\lambda_{r}$ and $\eta_{r}$ are the $r$ th real eigenvalue and loss factor, respectively. If $\left[\Phi_{r}^{*}\right]$ is approximated by a undamped mode shape $\left[\Phi_{r}\right]$, the $r$ th loss factor can be approximated by

$$
\eta_{r}=\frac{\left\{\Phi_{r}\right\}^{T}\left[K_{v}\right]\left\{\Phi_{r}\right\}}{\left\{\Phi_{r}\right\}^{T}[K]\left\{\Phi_{r}\right\}}
$$

In order to take several modes into account simultaneously, a weighted function of loss factors is defined as follows:

$$
F=\sum_{j}^{N} \alpha_{j} \eta_{j}
$$

where $\alpha$ is the weighted factor and $N$ is the number of interested modes. In general, the vibratory energy in the low frequency band is greater than that in high frequency band and the value of $N$ in [51] is set as 3. Thus, the value of $\alpha$ is 1 and the value of $N$ is 3 here.

\section{Finite Element Model Validation}

Although the transverse shear stress continuity between the base beam and the viscoelastic layer was not taken into account, the finite element model presented in this study is capable of handling CLD treatments with a relatively thin viscoelastic layer. This is verified by comparing the model presented here with that presented by Lesieutre and Lee [30].

A cantilever beam with length $L(500 \mathrm{~mm})$ and width $b$ $(12 \mathrm{~mm})$ was used in this study. In this section, viscoelastic material properties are considered to be constant for the sake of simplicity. Values used for storage shear modulus and loss factor are $G_{v}=1.5 \mathrm{MPa}$ and $\eta=1.1$, respectively. The base beam thickness and the constraining layer thickness are $h_{b}=$ $5 \mathrm{~mm}$ and $h_{c}=5 \mathrm{~mm}$, respectively.

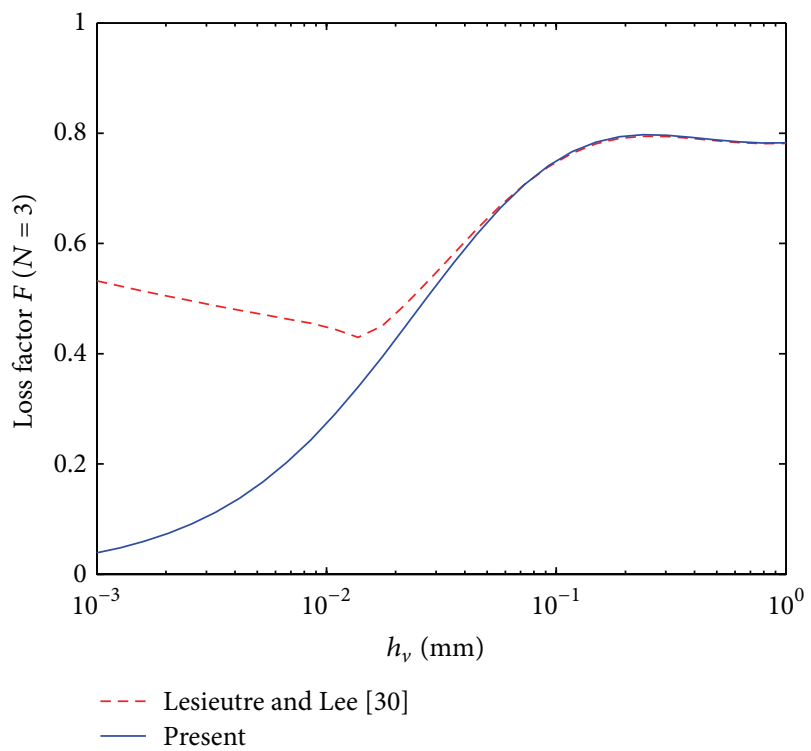

FIGURE 5: Comparison of Lesieutre's model and the present model.

Comparison of the two finite element models is illustrated in Figure 5. Lesieutre's model was based on the IDSS theory, whereas the model in this study incorporates the shear stress continuity condition. Loss factor values were calculated from the two models. It can be seen from the figure that the loss factors match well except for treatments with relatively thin viscoelastic layer. The IDSS theory based models result in incorrect values due to singularities in the stiffness matrix. This problem was observed once again in cases where the beam parameters were changed. This renders the IDSS theory based models inadequate for parametric analysis of CLD treatments.

To further validate the finite element formulation, frequency and loss factor results from the present model were compared to those from the shell/solid/shell (SSS) model. Results from the shell/solid/shell (SSS) model were obtained using complex eigensolution and were assumed to be accurate. Symmetric configurations were analyzed here since the mode shape approximation involved in the MSE method significantly affects the loss factor results for symmetric configurations [51]. The following dimensional ratios are defined to allow universal comparison of results. It is assumed that the viscoelastic layer undergoes pure shear. As stated in [7], this assumption is valid only when the viscoelastic layer is relatively thin and the viscoelastic layer thickness is not in the same order as the base beam. Thus, viscoelastic layer thickness ratio is defined in terms of the base beam thickness:

$H_{b}=h_{b} / L$, base beam thickness ratio.

$H_{c}=h_{c} / L$, constraining layer thickness ratio.

$H_{v}=h_{v} / h_{b}$, viscoelastic layer thickness ratio.

$n$, number of cuts.

$0<X_{1}<\cdots<X_{n}<1$, position of cuts $\left(X_{n}=x_{n} / L\right.$, where $x_{n}$ is the $x$ coordinate of the cut). 
TABLE 2: Comparison between present model and SSS model on frequencies and loss factors for various values of $H_{v}$ and $G_{v}\left(H_{b}=H_{c}=0.001\right.$, $n=0)$.

\begin{tabular}{lccccccccr}
\hline & & \multicolumn{3}{c}{$H_{v}=0.2$} & & \multicolumn{3}{c}{$H_{v}=0.4$} \\
& Present & SSS & Error & Present & SSS & Error & Present & SSS & Error \\
\hline$G_{v}=1.5$ & & & & & & & & & \\
$\mathrm{MPa}$ & & & & & & & & & \\
$f_{1}(\mathrm{~Hz})$ & 3.57 & 3.57 & $0.0 \%$ & 3.94 & 3.95 & $0.3 \%$ & 4.30 & 4.31 & $0.2 \%$ \\
$f_{2}(\mathrm{~Hz})$ & 21.4 & 21.5 & $0.5 \%$ & 22.7 & 22.9 & $0.9 \%$ & 23.9 & 24.2 & $1.2 \%$ \\
$f_{3}(\mathrm{~Hz})$ & 56.5 & 56.9 & $0.7 \%$ & 57.6 & 58.4 & $1.4 \%$ & 58.7 & 59.9 & $2.0 \%$ \\
$F(N=3)$ & 0.314 & 0.307 & $2.3 \%$ & 0.531 & 0.507 & $4.7 \%$ & 0.699 & 0.656 & $6.6 \%$ \\
$G_{v}=5$ & & & & & & & & & \\
$\mathrm{MPa}$ & & & & & & & & & \\
$f_{1}(\mathrm{~Hz})$ & 3.59 & 3.59 & $0.0 \%$ & 3.99 & 3.99 & $0.0 \%$ & 4.38 & 4.38 & $0.0 \%$ \\
$f_{2}(\mathrm{~Hz})$ & 22.2 & 22.2 & $0.0 \%$ & 24.3 & 24.3 & $0.0 \%$ & 26.7 & 26.4 & $1.1 \%$ \\
$f_{3}(\mathrm{~Hz})$ & 60.7 & 60.8 & $0.2 \%$ & 65.2 & 65.5 & $0.5 \%$ & 69.2 & 69.6 & $0.6 \%$ \\
$F(N=3)$ & 0.118 & 0.117 & $0.9 \%$ & 0.227 & 0.223 & $1.8 \%$ & 0.328 & 0.322 & $1.9 \%$ \\
\hline
\end{tabular}

Table 2 shows natural frequencies, loss factors, and corresponding errors based on the two finite element models and illustrates the effect of varying the viscoelastic layer thickness and the storage modulus of viscoelastic material. The increase of viscoelastic layer thickness does not significantly affect the errors in natural frequencies but results in an increase in loss factor errors. The finite element model presented in this study is valid when $H_{v}$ is under 0.6. The storage modulus variation significantly affects loss factor results. Thus, the effect of frequency variation on storage modulus and loss factor of viscoelastic material should not be overlooked. An iterative method presented in [39] was adopted here to revise the MSE method. The iterative method approaches accurate storage modulus by updating the storage modulus and corresponding natural frequency over multiple iterations. The natural frequency approaches its accurate value after the first iteration step and hence calculations were stopped after the first iteration step. Flowchart illustrating the calculation procedure for the modal loss factors is shown in Figure 6.

Effect of varying base beam thickness and initiating a cut at position $X_{1}=0.5$ is illustrated in Table 3. For fullcover CLD beams, the base layer thickness variation has no significant effect on calculation errors for natural frequencies and loss factors. On the contrary, initiating a cut into the treatment has a significant effect on the calculation errors in loss factors. For symmetric CLD beams, the aforementioned finite element model is valid when $H_{b}$ is under 0.012 .

\section{Parametric Analysis and Optimization}

4.1. Effect of Geometry Parameters and Material Properties. The shear strain in the viscoelastic layer, promoted by the constraint effect of the constraining layer, is directly responsible for the damping mechanism developed in CLD treatments. The thickness variation of base beam layer has a direct effect on the shear strain level, as discussed in preceding sections. Relationship between the base beam thickness and the effectiveness of an arbitrarily placed cut is first discussed.

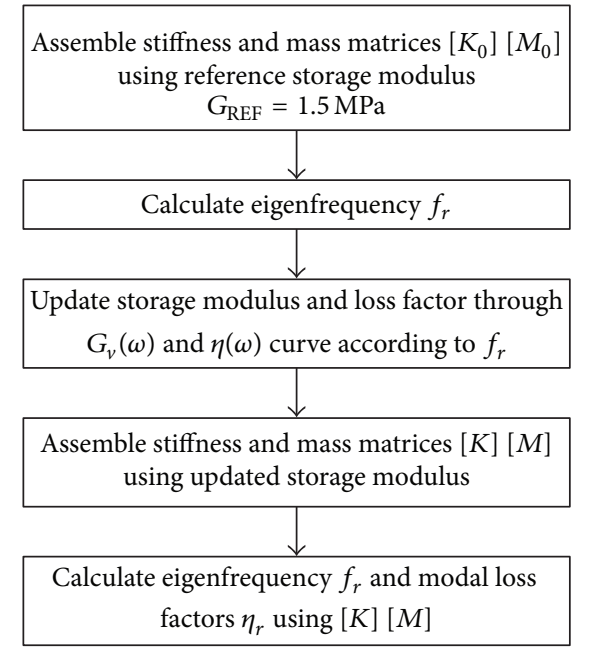

FIGURE 6: Flowchart illustrating the $r$ th modal loss factor calculation.

In this section, absolute layer thickness refers to calculations under the condition that the length of the beam is $500 \mathrm{~mm}$.

As stated in [44], a cut should be placed at the maximum flexural displacement where the bending moment is maximal and the shear strain in the viscoelastic layer is not significant. Mode shapes for full-cover CLD beams are illustrated in Figure 7 and the position of maximum flexural displacement for the third mode is identified. Based on the results, the cut is placed at $X_{1}=0.74$.

Figure 8 shows the damping efficiency versus viscoelastic layer thickness curves for symmetric CLD beams where the line without marks represents full-cover and the line with marks represents segmented beams. For the beam with ratio $H_{b}=0.001$, placing a cut at position $X_{1}=0.74$ is always a feasible way to increase damping efficiency. The shell/solid/ shell model was employed to analyze treatments with thicker viscoelastic layer. Results show that segmentation remains efficient when the viscoelastic layer has the same thickness 
TABLE 3: Comparison between present model and SSS model on frequencies and loss factors for various values of $H_{b}$ and $n\left(H_{b}=H_{c}, H_{v}=0.4\right.$, $\left.X_{1}=0.5, G_{v}=1.5\right)$.

\begin{tabular}{lccccccccc}
\hline & & $H_{b}=0.01$ & & \multicolumn{3}{c}{$H_{b}=0.012$} & \multicolumn{3}{c}{$H_{b}=0.015$} \\
& Present & SSS & Error & Present & SSS & Error & Present & SSS & Error \\
\hline$n=0$ & & & & & & & & & \\
$f_{1}(\mathrm{~Hz})$ & 24.4 & 25.1 & $2.8 \%$ & 27.2 & 28.0 & $2.9 \%$ & 31.4 & 32.0 \\
$f_{2}(\mathrm{~Hz})$ & 111 & 112 & $0.9 \%$ & 129 & 130 & $0.8 \%$ & 156 & 156 & $0.0 \%$ \\
$f_{3}(\mathrm{~Hz})$ & 284 & 284 & $0.0 \%$ & 335 & 335 & $0.0 \%$ & 413 & 412 & $0.2 \%$ \\
$F(N=3)$ & 0.8 & 0.749 & $6.8 \%$ & 0.721 & 0.675 & $6.8 \%$ & 0.611 & 0.575 & $6.3 \%$ \\
$n=1$ & & & & & & & & \\
$f_{1}(\mathrm{~Hz})$ & 18.9 & 18.8 & $0.5 \%$ & 21.5 & 21.3 & $0.9 \%$ & 25.6 & 24.7 \\
$f_{2}(\mathrm{~Hz})$ & 101 & 96.0 & $5.2 \%$ & 119 & 112 & $6.3 \%$ & 147 & $3.6 \%$ \\
$f_{3}(\mathrm{~Hz})$ & 283 & 283 & $0.0 \%$ & 334 & 333 & $0.3 \%$ & 412 & 400 \\
$F(\mathrm{~N}=3)$ & 0.542 & 0.545 & $0.6 \%$ & 0.431 & 0.453 & $4.9 \%$ & 0.313 & 0.412 & $24.0 \%$ \\
\hline
\end{tabular}
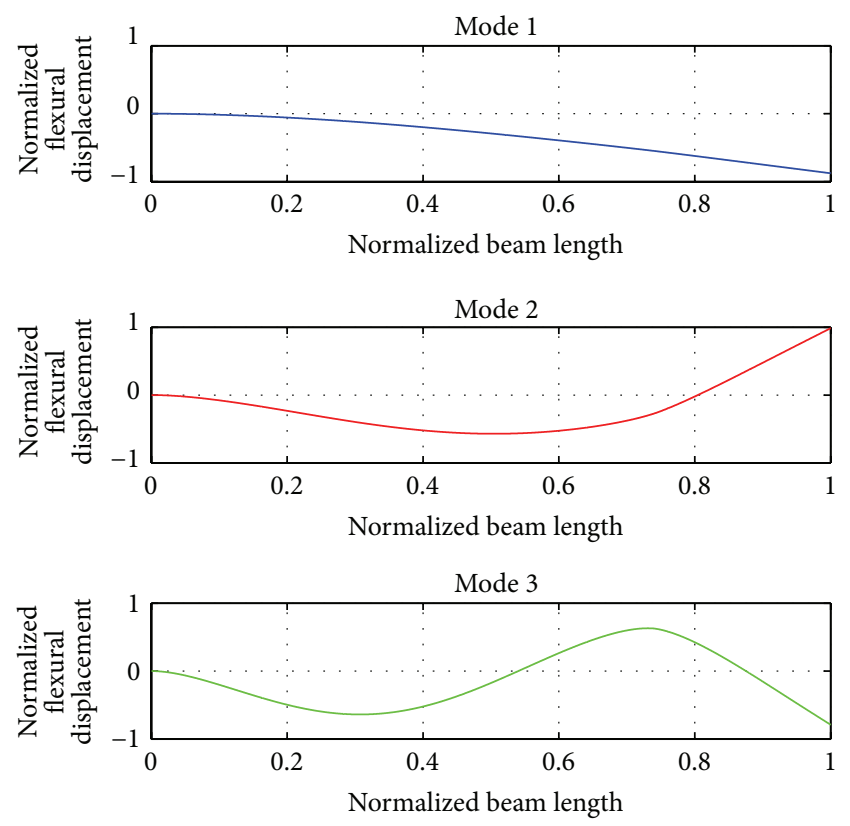

Figure 7: Mode shapes for full-cover CLD beams.

as the base beam $\left(h_{v}=h_{b}=0.5 \mathrm{~mm}\right)$. (To make a comparison between CLD beams with different $H_{b}$, the absolute viscoelastic layer thickness $h_{v}$ is used here.) However, for beams with ratios $H_{b}=0.012$ and $H_{b}=0.005$, segmentation is inefficient for cases where the viscoelastic layer thickness exceeds $0.2 \mathrm{~mm}$.

An efficiency curve illustrates a combination of the volume energy and the shear strain field inside the viscoelastic layer [51]. The volume energy has a direct linear relation with the viscoelastic layer thickness. For low shear strains, the efficiency curve should be a monotonic increasing line, similar to the solid line in Figure 8 . As the ratio $H_{b}$ varies from 0.001 to 0.012 , a sharp increase in the loss factor for very thin viscoelastic layers was observed. This implies that the shear strain level increases with increase in base layer thickness. Whenever a cut is initiated in the damping treatment, the shear strain field is reshaped. Provided that the viscoelastic

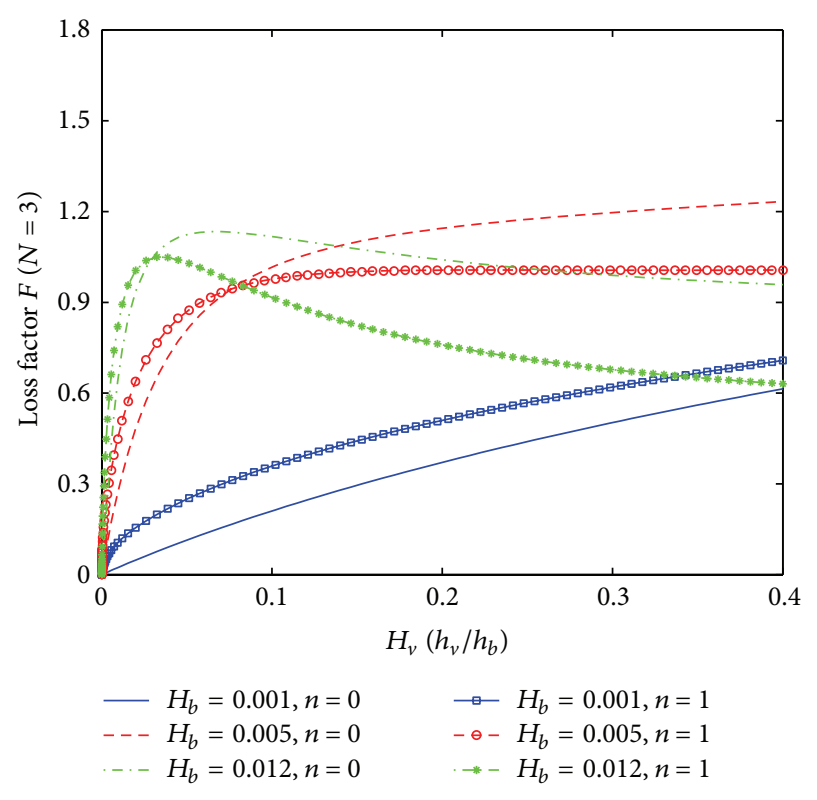

FIgURE 8: Efficiency curves for full-cover and segmented CLD beams with various values of $H_{b}\left(H_{b}=H_{c}\right)$.

layer is not particularly thin $\left(h_{v}>0.2 \mathrm{~mm}\right)$, placing a cut at the position $X_{1}=0.74$ increased the damping efficiency for the beam with ratio $H_{b}=0.001$, whereas a decrease in the damping efficiency was observed for ratio $H_{b}=0.012$ or $H_{b}=0.005$. Figure 9 shows a comparison of the shear strain field for the full-cover CLD beam with ratio $H_{b}=0.001$ and the corresponding segmented one. It can be seen that placing a cut creates a high-shear region at that position, although the shear strain at other positions decreases slightly. Comparisons for CLD beams with ratio $H_{b}=0.005$ or $H_{b}=0.012$ are depicted in Figures 10 and 11, respectively. It is apparent that placing a cut reduces the global shear strain especially at the tip of the beam.

For three CLD beams with different base beam ratios in Figures 9-11, the viscoelastic layer thickness was $0.25 \mathrm{~mm}$. A comparison among the three beams shows that a thicker base layer thickness leads to a more intense shear strain pattern. 

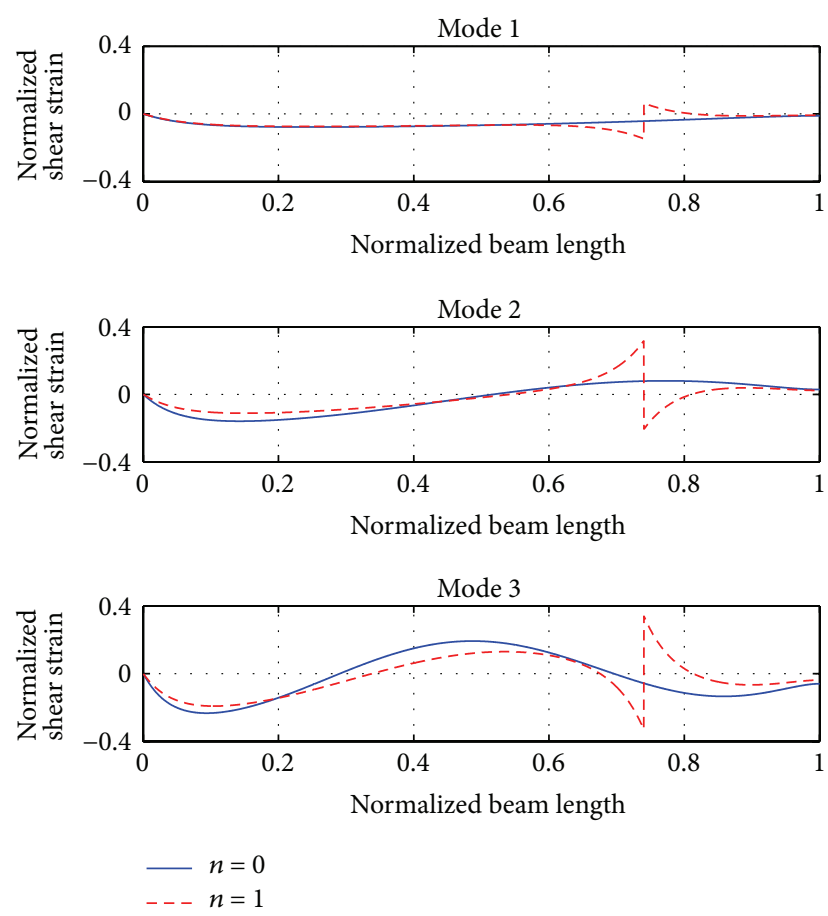

FIGURE 9: Comparison of the shear strain field between full-cover and segmented CLD beams with ratio $H_{b}=H_{c}=0.001$.

Segmentation is not always an effective method to increase the shear strain in the viscoelastic layer. To a large extent, the effectiveness of placing a cut is dependent on the original shear strain level. For CLD treatments with high levels of shear strain, placing a cut would reduce the original shear strain field and consequently reduce the damping efficiency. On the other hand, for CLD treatments with low levels of shear strain, placing a cut would create a high-shear region and thereby increase the damping efficiency.

Thickness variance of the viscoelastic layer also affects the shear strain field. As a matter of fact, for the same flexural pattern produced by two face layers, a thinner viscoelastic layer will present more transverse shear strain than a thicker one. Segmentation is effective when the viscoelastic layer is relatively thin. As for CLD beams with extremely thin viscoelastic layer $\left(h_{v} \leq 0.2 \mathrm{~mm}\right)$, segmentation is always effective, although the shear strain level is high. This can be attributed to the fact that segmentation is easier to reduce the shear strain field in a thicker viscoelastic layer rather than a thinner one. However, structural damping rate is relatively low since volume of viscoelastic material is very small.

Viscoelastic layer thickness variation affects the applicability of segmentation in a different way and is considered individually. Regardless of the influence of the viscoelastic layer thickness variation, the effectiveness of segmentation is dependent on the shear strain level inside the viscoelastic layer. A coarse approximation for the shear strain in the viscoelastic layer of full-cover CLD beams can be made based on the shape of the efficiency curve. As depicted in Figure 8, peak values for very thin viscoelastic layers become increasingly obvious with increase in the shear strain. Effect of
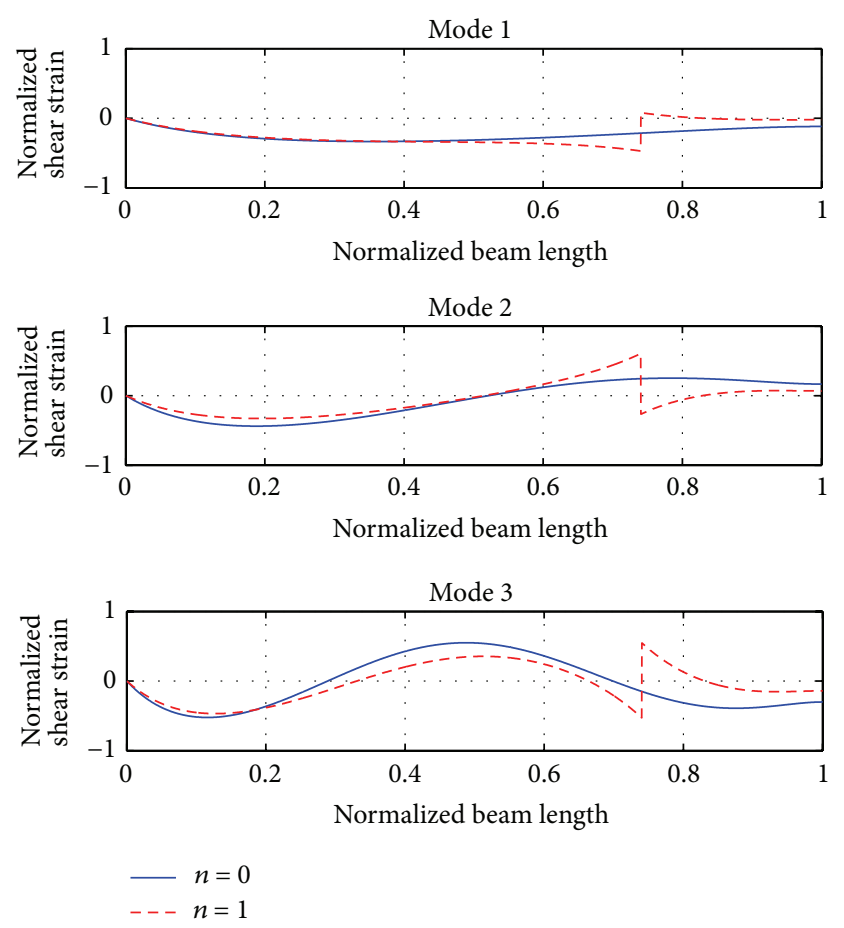

FIGURE 10: Comparison of the shear strain field between full-cover and segmented CLD beams with ratio $H_{b}=H_{c}=0.005$.

the constraining layer thickness variation on the shear strain field is shown in Figure 12. It can be seen that peak values are increasingly observed as the thickness of constraining layer is increased. This implies that thicker constraining layers produce more shear strain and this conclusion is in line with existing studies $[7,25]$. Another observation is that placing a cut at $X_{1}=0.74$ remains effective for CLD beams with relatively thin viscoelastic layers.

Regardless of the influence of the viscoelastic layer thickness variation, the shape of the damping efficiency curve represents the shear strain level. Hence, it can be used to explore the effect of other design parameters. Effect of material properties on the shear strain field is shown in Figure 13. A full-cover CLD beam with ratio $H_{b}=H_{c}=$ 0.012 was adopted and values of $G_{0}$ and $E_{0}$ were $1.5 \mathrm{MPa}$ and $68 \mathrm{GPa}$, respectively. Results show that adopting stiffer face layer material or softer viscoelastic material results in increasing occurrence of the peak, which implies that the shear strain level is higher.

In summary, increasing stiffness of the two face layers or adopting relatively soft viscoelastic material would result in higher levels of shear strain in the viscoelastic layer, which renders segmentation useless. An example is presented to further illustrate this point. Optimal cut arrangements were obtained for a CLD beam with selected parameters in [42]. Parameters and properties of the CLD beam were $L=$ $500 \mathrm{~mm}, b=30 \mathrm{~mm}, h_{b}=5 \mathrm{~mm}, h_{v}=2 \mathrm{~mm}, h_{c}=0.5 \mathrm{~mm}$, $E_{b}=E_{c}=200 \mathrm{GPa}, \rho_{b}=\rho_{c}=7800 \mathrm{~kg} / \mathrm{m}^{3}, G_{v}=24 \mathrm{MPa}$, and $\rho_{v}=1616 \mathrm{~kg} / \mathrm{m}^{3}$. Figure 14 shows the damping efficiency curve, which was based on the finite element model in the present work. The curve is approximate to a monotonically 

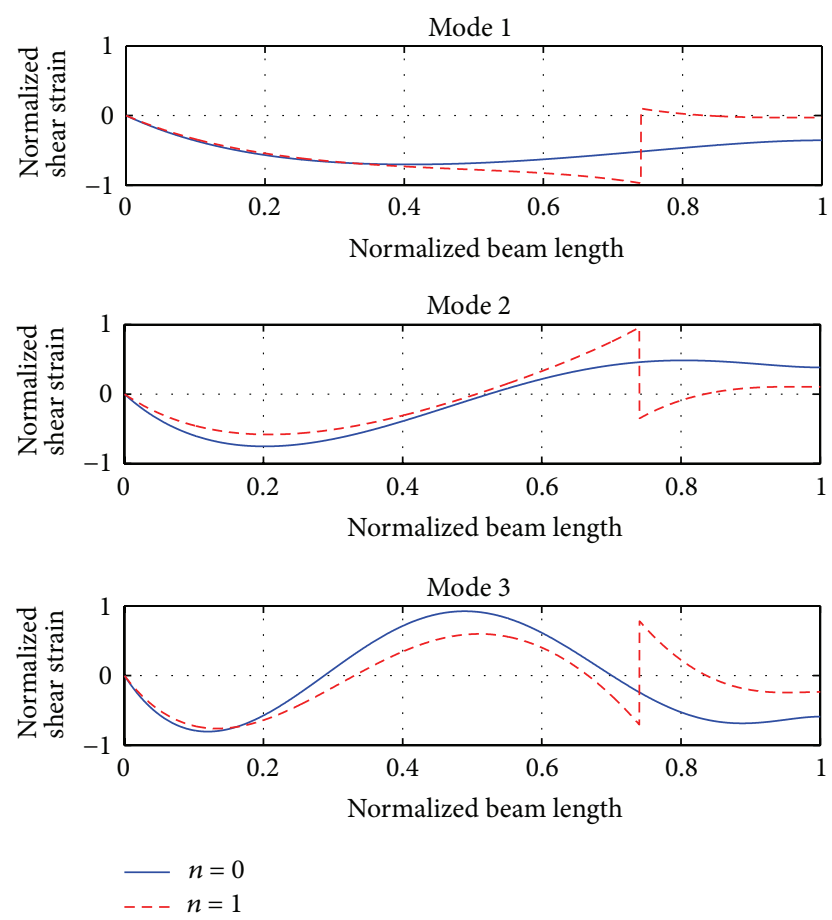

FIGURE 11: Comparison of the shear strain field between full-cover and segmented CLD beams with ratio $H_{b}=H_{c}=0.012$.

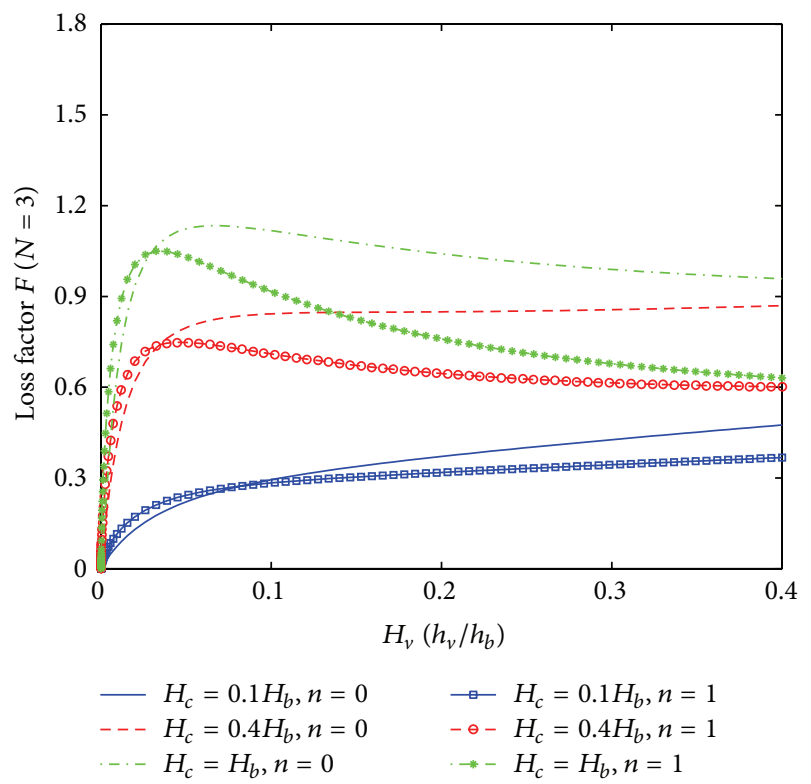

FIGURE 12: Efficiency curves for full-cover and segmented CLD beams with various values of $H_{c}\left(H_{b}=0.012\right)$.

increasing line. This suggests that the shear strain level is low. Therefore, placing cuts at appropriate position could improve structural damping ratio, as long as the viscoelastic layer thickness is within reasonable limits $\left(h_{v} \leq h_{b}\right)$.

4.2. Cuts Arrangement Optimization. In the previous subsection, the cut was placed arbitrarily. Furthermore, in order

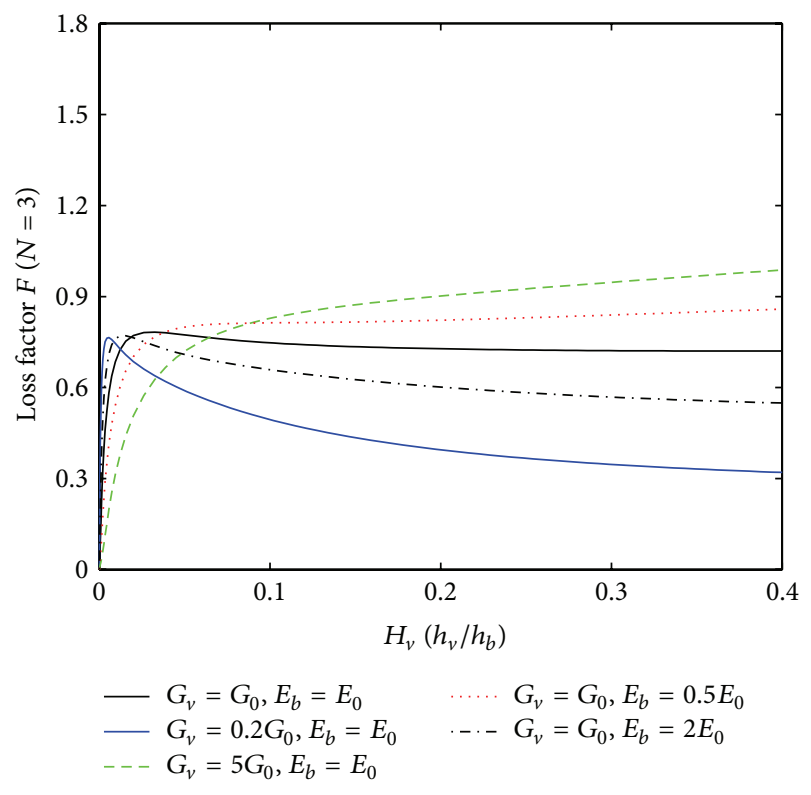

FIGURE 13: Efficiency curves for CLD beams with various material properties $\left(H_{b}=H_{c}=0.012\right)$.

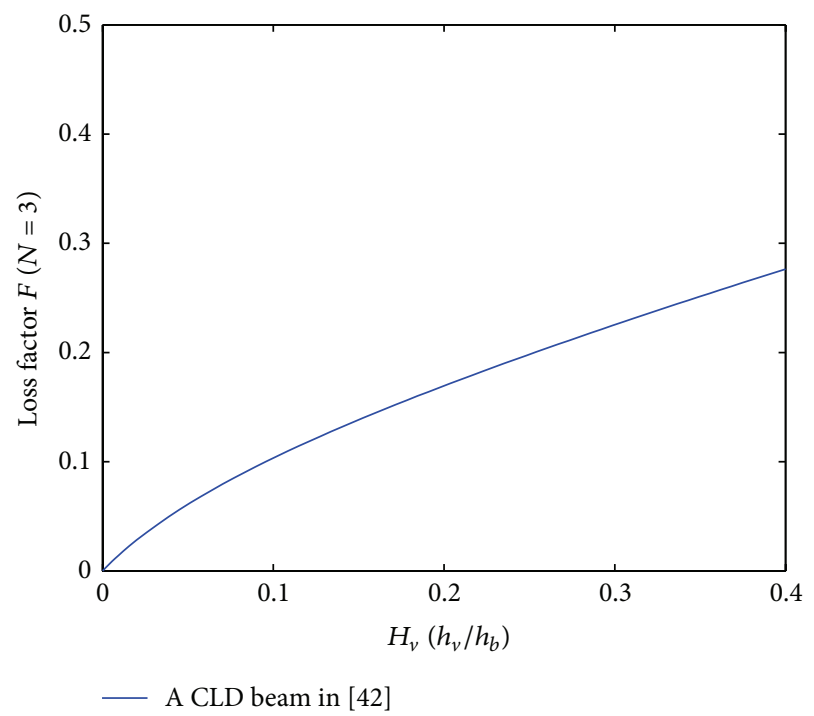

FIGURE 14: Efficiency curve for a selected CLD beam in [42].

to explore whether a cut placed at an optimum position could further increase the damping efficiency, a genetic algorithm was adopted to optimize cut arrangement. Thickness variation in the viscoelastic layer affects the applicability of segmentation in a different way. Thus, the optimum value of the viscoelastic layer thickness was selected here. For a full-cover beam with $H_{b}=H_{c}=0.012$, as shown in Figure 8, optimal thickness of viscoelastic layer is the value corresponding to the peak of the loss factor. For $H_{b}=H_{c}=$ 0.001 , optimal thickness is the maximum value by taking weight limitation into consideration. From Figure 8, it can be seen that placing a cut would slightly shift the peak of 


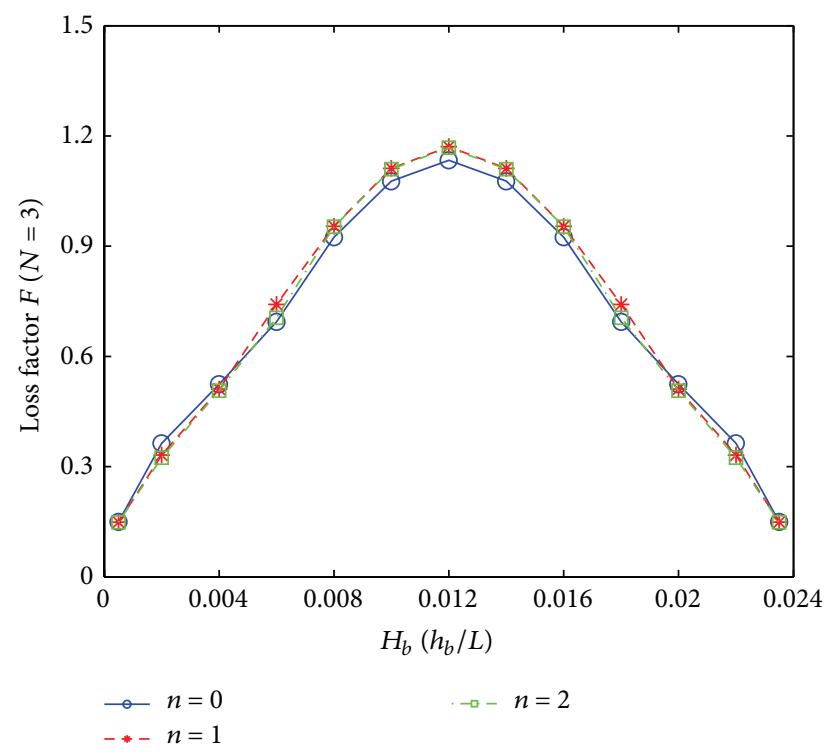

FIGURE 15: Optimized loss factor results for symmetric and asymmetric CLD configurations $\left(H_{b}+H_{c}=0.024\right)$.

the loss factor. As a result, viscoelastic layer thickness was also regarded as an optimization variable.

Asymmetric constrained configurations are used extensively as well as symmetric configurations. Subject to a weight limitation, asymmetric and symmetric configurations were compared. Weight of the viscoelastic layer was neglected. Provided that total thickness of the base layer and that of constraining layer were equal for different CLD configurations, weight of these configurations was considered to be the same. As stated previously, the MSE method uses approximate undamped mode shapes to calculate loss factors. This has a major effect on symmetric CLD configurations. Therefore, the present model was assumed to be valid for asymmetric configurations provided that it was valid for the corresponding symmetric case.

Genetic algorithm used here is different from conventional optimization procedures and does not require derivatives. Moreover, it can be applied to any kind of objective functions with any constraints. In addition, the ergodicity of evolution operations renders the genetic algorithm effective at performing global search. The algorithm was implemented using the Matlab optimization Toolbox. The optimization solution was stopped after 100 iterations with a population size of 40 and mutation probability equal to 0.8 . For the case that the sum of $H_{b}$ and $H_{c}$ is 0.024 , the optimization problem is written as follows:

$$
\begin{array}{cl}
\text { Minimize: } & \frac{1}{F\left(X_{1}, X_{2}, \ldots, X_{n}, H_{v}\right)}, \\
\text { Subject to: } & 0<X_{1}<\cdots<X_{n}<1, \\
& 0<H_{v} \leq 0.4,
\end{array}
$$

where $F$ is the weighted function of loss factors.

Figure 15 shows the optimized loss factor results for

\begin{tabular}{|c|c|c|c|c|c|c|c|}
\hline & $H_{b}=0.012$ & 0.014 & 0.016 & 0.018 & 0.02 & 0.022 & 0.0235 \\
\hline \multicolumn{8}{|l|}{$n=0$} \\
\hline$H_{v}$ & 0.067 & 0.059 & 0.058 & 0.041 & 0.396 & 0.400 & 0.400 \\
\hline \multicolumn{8}{|l|}{$n=1$} \\
\hline$H_{v}$ & 0.052 & 0.046 & 0.042 & 0.042 & 0.061 & 0.400 & 0.400 \\
\hline$X_{1}$ & 0.900 & 0.900 & 0.896 & 0.877 & 0.900 & 0.900 & 0.900 \\
\hline \multicolumn{8}{|l|}{$n=2$} \\
\hline$H_{v}$ & 0.051 & 0.044 & 0.042 & 0.027 & 0.056 & 0.394 & 0.400 \\
\hline$X_{1}$ & 0.0891 & 0.891 & 0.890 & 0.844 & 0.877 & 0.887 & 0.891 \\
\hline$X_{2}$ & 0.900 & 0.900 & 0.899 & 0.855 & 0.887 & 0.896 & 0.900 \\
\hline
\end{tabular}
different CLD configurations. Notice that if the constraining
TABLE 4: Final values of design variables $\left(H_{b}+H_{c}=0.024\right)$.

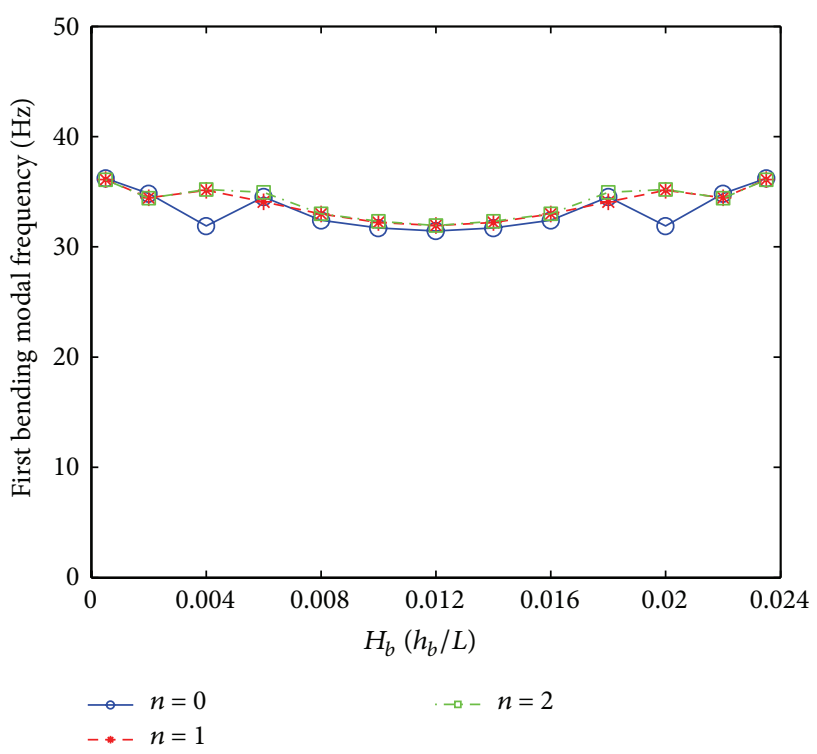

FIGURE 16: Natural frequency results for symmetric and asymmetric CLD configurations $\left(H_{b}+H_{c}=0.024\right)$.

layer thickness exceeds the base layer thickness, the two face layers exchange their roles and the thinner one was cut all the time. Thus, the optimized loss factor versus base beam ratio curve in Figure 15 is symmetric. Three curves are illustrated for different cut arrangements. It was observed for all cases that symmetric configurations provided the largest damping, subject to a weight limitation. In addition, it was seen that, for a specific CLD configuration, placing no cut, one cut, or two cuts in the damping treatment resulted in similar damping. As shown in Table 4, optimal locations of cuts are at the tip of the beam for all cases. This indicates that the continuity of the constraining layer is of paramount importance for maintaining a high-shear strain level in the viscoelastic layer. In other words, segmentation is inadequate for improving damping performance for the case where sum of $H_{b}$ and $H_{c}$ is 0.024 . Corresponding modal frequency results are shown in Figure 16. It can be seen that the stiffness of symmetric configurations does not decrease significantly in comparison to asymmetric configurations.

Subsequently, the damping optimization methodology was applied to the case where the sum of $H_{b}$ and $H_{c}$ was 0.002 . 


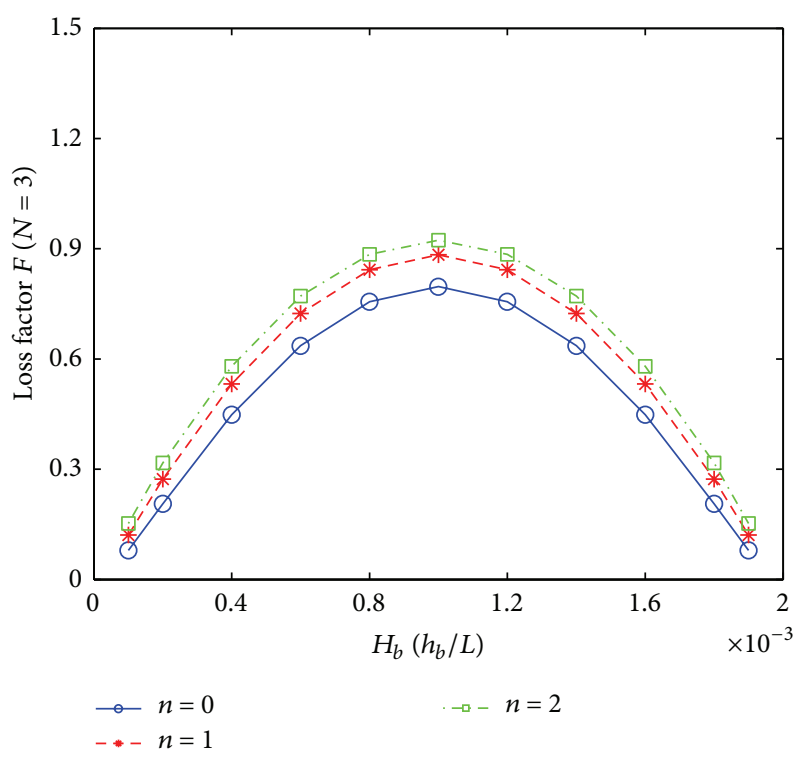

FIGURE 17: Optimized loss factor results for different CLD configurations $\left(H_{b}+H_{c}=0.002\right)$.

For a beam with ratio $H_{b}=0.001$, an increase in the damping is mainly dependent on introducing additional viscoelastic material. Thus, the volume of the viscoelastic material was restricted and the absolute thickness of the viscoelastic layer was regarded as a design variable instead of the thickness ratio $H_{v}$. Then, the optimization problem can be written as follows:

$$
\begin{array}{ll}
\text { Minimize: } & \frac{1}{F\left(X_{1}, X_{2}, \ldots, X_{n}, h_{v}\right)}, \\
\text { Subject to: } & 0<X_{1}<\cdots<X_{n}<1, \\
& 0<h_{v} \leq 0.3 \mathrm{~mm},
\end{array}
$$

where $F$ is the weighted function of loss factors.

Optimized loss factor results are shown in Figure 17. Maximum values of loss factors correspond to the symmetric configurations. Moreover, an obvious improvement can be observed when results for full-cover CLD beam and segmented CLD beam are compared. Final values of design variables are listed in Table 5. As expected, optimal thickness of viscoelastic layer is the maximum value. It is proposed that the cuts be placed in the middle of the CLD beam. This implies that a high-shear region is created at this position. First modal frequencies for the above CLD configurations are presented in Figure 18 and it is apparent that placing cuts increases compliance of the beam.

Table 6 lists optimized loss factor results for symmetric sandwich beams with different base beam thickness ratios. It can be seen that, for the cases where $H_{b}$ is greater than 0.002 , optimal locations of cuts are at the tip of the beam. Placing cuts enhances the damping capacity for CLD beams with base beam thickness ratio $H_{b}$ under 0.002 , namely, flexible beams. In summary, for the case that the original shear strain level is high, segmentation is not an effective method to increase structural damping rate even if the cut arrangement was optimized.
TABLE 5: Final values of design variables $\left(H_{b}+H_{c}=0.002\right)$.

\begin{tabular}{ccccccc}
\hline \multicolumn{1}{c}{$H_{b}=0.001$} & 0.0012 & 0.0014 & 0.0016 & 0.0018 & 0.0019 \\
\hline $\begin{array}{c}n \\
\quad\end{array}(\mathrm{~mm})$ & 0.300 & 0.300 & 0.300 & 0.300 & 0.300 & 0.300 \\
$n=1$ & & & & & & \\
$\quad h_{v}(\mathrm{~mm})$ & 0.300 & 0.300 & 0.300 & 0.300 & 0.300 & 0.300 \\
$X_{1}$ & 0.535 & 0.536 & 0.539 & 0.580 & 0.650 & 0.667 \\
$n=2$ & & & & & & \\
$h_{v}(\mathrm{~mm})$ & 0.300 & 0.300 & 0.300 & 0.300 & 0.300 & 0.300 \\
$X_{1}$ & 0.167 & 0.171 & 0.172 & 0.192 & 0.171 & 0.337 \\
$X_{2}$ & 0.563 & 0.585 & 0.583 & 0.738 & 0.656 & 0.674 \\
\hline
\end{tabular}

TABLE 6: Optimization results for symmetric CLD beams.

\begin{tabular}{cccccccc}
\hline$H_{b}+H_{c}$ & $H_{b}$ & $H_{c}$ & $H_{v}$ & $n$ & {$\left[X_{1} X_{2} \cdots X_{n}\right]$} & $F(N=3)$ & $f_{1} / \mathrm{Hz}$ \\
\hline \multirow{2}{*}{0.024} & 0.012 & 0.012 & 0.067 & 0 & - & 1.13 & 31.4 \\
& 0.012 & 0.012 & 0.052 & 1 & {$[0.90]$} & 1.17 & 31.9 \\
\hline \multirow{2}{*}{0.02} & 0.01 & 0.01 & 0.089 & 0 & - & 1.14 & 26.5 \\
& 0.01 & 0.01 & 0.073 & 1 & {$[0.95]$} & 1.17 & 26.8 \\
\hline \multirow{2}{*}{0.016} & 0.008 & 0.008 & 0.147 & 0 & - & 1.14 & 21.4 \\
& 0.008 & 0.008 & 0.113 & 1 & {$[0.93]$} & 1.17 & 21.7 \\
\hline \multirow{2}{*}{0.012} & 0.006 & 0.006 & 0.4 & 0 & - & 1.21 & 16.2 \\
& 0.006 & 0.006 & 0.4 & 1 & {$[0.96]$} & 1.21 & 16.2 \\
\hline \multirow{2}{*}{0.008} & 0.004 & 0.004 & 0.4 & 0 & - & 1.24 & 12.3 \\
& 0.004 & 0.004 & 0.4 & 1 & {$[0.93]$} & 1.27 & 12.3 \\
\hline \multirow{2}{*}{0.004} & 0.002 & 0.002 & 0.4 & 0 & - & 1.05 & 7.15 \\
& 0.002 & 0.002 & 0.4 & 1 & {$[0.90]$} & 1.10 & 7.15 \\
\hline \multirow{2}{*}{0.002} & 0.001 & 0.001 & 0.4 & 0 & - & $\mathbf{0 . 6 1 4}$ & 3.85 \\
& 0.001 & 0.001 & 0.4 & 3 & {$[0.170 .56$} & $\mathbf{0 . 8 1 7}$ & 2.34 \\
\hline
\end{tabular}

\section{Conclusions}

In the present study, a dimensionless analysis was conducted on segmented CLD treatments. The effectiveness of segmentation to enhance the damping capacity of CLD treatments was discussed. A finite element model capable of handling treatments with relatively thin viscoelastic layer was developed based on interlaminar continuous shear stress theories and the model was validated by comparison with the classical shell/solid/shell model. Structural damping ratios were estimated using the modal strain energy method.

The applicability of segmentation was analyzed in terms of shear strain. This is due to the fact that the shear strain field inside the viscoelastic layer is responsible for the damping efficiency of the treatment. It was found that the viscoelastic layer thickness variation affected the effectiveness of segmentation in a different way. Segmentation was found to be effective only when the viscoelastic layer was relatively thin. When the viscoelastic layer thickness was under $0.2 \mathrm{~mm}(L=$ $500 \mathrm{~mm}$ ), placing cuts was found to be always effective in increasing the damping efficiency. Provided that the optimal thickness of viscoelastic layer was selected, the applicability of segmentation was dependent on the shear strain level 


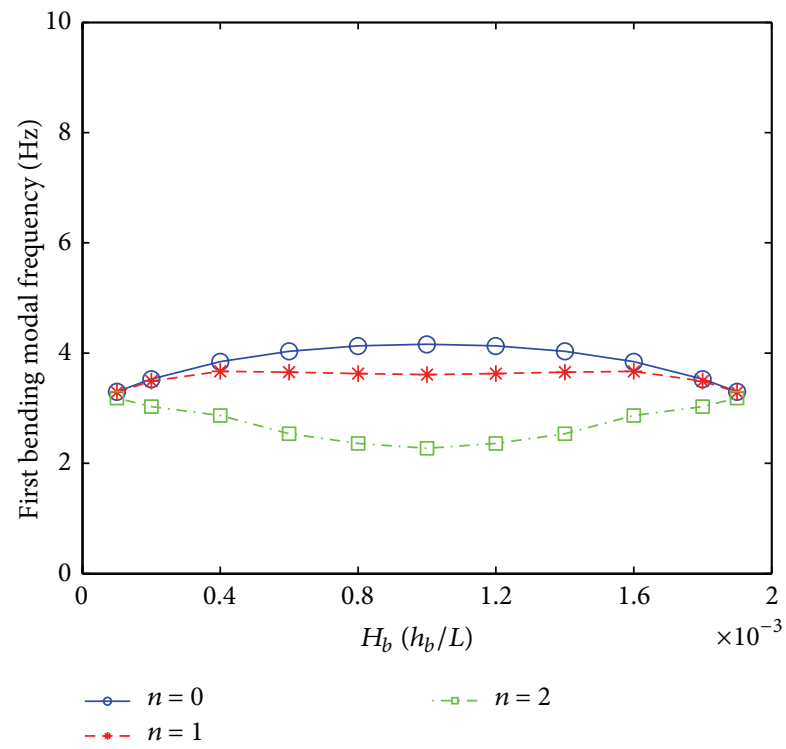

Figure 18: Natural frequency results for different CLD configurations $\left(H_{b}+H_{c}=0.002\right)$.

inside the viscoelastic layer. If the shear strain level was high, placing cuts would reduce the original shear strain field. If the shear strain level was low, placing cuts would create a high-shear region in the viscoelastic layer, thereby increasing the damping efficiency. Moreover, adopting relatively soft viscoelastic material or increasing stiffness of the two face layers could build up a higher shear strain level in the viscoelastic layer. The above conclusions were valid even if the cut arrangement was optimized. In addition, symmetric configurations were found to be superior to asymmetric ones subject to a weight limitation.

When dealing with CLD beams, designers typically choose relatively thin but not extremely thin viscoelastic layers (under $0.2 \mathrm{~mm}$ ). Hence, the first key to improve the damping efficiency is to raise the shear strain level inside the viscoelastic layer. Adopting relatively soft viscoelastic material and increasing stiffness of face layers are both available strategies. However, this would lead to segmentation being useless. For flexible CLD beams or asymmetric CLD beams with relatively thin viscoelastic layer, the shear strain level inside the viscoelastic layer is low. Placing cuts at appropriate positions would improve the damping efficiency but would also increase compliance of the beam.

\section{Appendix}

Mass and stiffness matrices for the CLD beam:

$$
\begin{aligned}
& {\left[K^{(e)}\right]=\left[K_{E}^{(e)}\right]+\left[K_{G}^{(e)}\right],} \\
& {\left[K_{E}^{(e)}\right]=\left[\begin{array}{lll}
{\left[K_{E u u}\right]} & {\left[K_{E u w}\right]} & {\left[K_{E u \beta}\right]} \\
{\left[K_{E u w}^{T}\right]} & {\left[K_{E w w}\right]} & {\left[K_{E w \beta}\right]} \\
{\left[K_{E u \beta}^{T}\right]} & {\left[K_{E w \beta}^{T}\right]} & {\left[K_{E \beta \beta}\right]}
\end{array}\right],}
\end{aligned}
$$

$$
\begin{aligned}
& {\left[K_{G}^{(e)}\right]=\left[\begin{array}{ccc}
{[0]} & {[0]} & {[0]} \\
{[0]} & {[0]} & {[0]} \\
{[0]} & {[0]} & {\left[K_{G \beta \beta}\right]}
\end{array}\right],} \\
& {\left[K_{E u u}\right]=A_{1} \int_{0}^{L_{e}}\left[N_{u}^{\prime}\right]^{T}\left[N_{u}^{\prime}\right] d x \text {, }} \\
& {\left[K_{E u w}\right]=A_{2} \int_{0}^{L_{e}}\left[N_{u}^{\prime}\right]^{T}\left[N_{w}^{\prime \prime}\right] d x,} \\
& {\left[K_{E u \beta}\right]=A_{3} \int_{0}^{L_{e}}\left[N_{u}^{\prime}\right]^{T}\left[N_{u}^{\prime}\right] d x,} \\
& {\left[K_{E w w}\right]=A_{4} \int_{0}^{L_{e}}\left[N_{w}^{\prime \prime}\right]^{T}\left[N_{w}^{\prime \prime}\right] d x,} \\
& {\left[K_{E w \beta}\right]=A_{5} \int_{0}^{L_{e}}\left[N_{w}^{\prime \prime}\right]^{T}\left[N_{u}^{\prime}\right] d x,} \\
& {\left[K_{E \beta \beta}\right]=A_{6} \int_{0}^{L_{e}}\left[N_{u}^{\prime}\right]^{T}\left[N_{u}^{\prime}\right] d x,} \\
& {\left[K_{G \beta \beta}\right]=A_{7} \int_{0}^{L_{e}}\left[N_{u}\right]^{T}\left[N_{u}\right] d x,} \\
& A_{1}=E_{b} b h_{b}+E_{c} b h_{c} \text {, } \\
& A_{2}=-E_{b} b \int_{-h_{b} / 2}^{h_{b} / 2} z d z-E_{c} b \int_{h_{b} / 2+h_{v}}^{h-h_{b} / 2} z d z, \\
& A_{3}=E_{c} b \int_{h_{b} / 2+h_{v}}^{h-h_{b} / 2}\left(k_{2} z^{2}+k_{1} z+k_{0}\right) d z, \\
& A_{4}=E_{b} b \int_{-h_{b} / 2}^{h_{b} / 2} z^{2} d z+E_{c} b \int_{h_{b} / 2+h_{v}}^{h-h_{b} / 2} z^{2} d z \\
& A_{5}=-E_{c} b \int_{h_{b} / 2+h_{v}}^{h-h_{b} / 2} z\left(k_{2} z^{2}+k_{1} z+k_{0}\right) d z \text {, } \\
& A_{6}=E_{c} b \int_{h_{b} / 2+h_{v}}^{h-h_{b} / 2}\left(k_{2} z^{2}+k_{1} z+k_{0}\right)^{2} d z, \\
& A_{7}=G_{v} b h_{v}+G_{c} b \int_{h_{b} / 2+h_{v}}^{h-h_{b} / 2}\left(2 k_{2} z+k_{1}\right)^{2} d z, \\
& {\left[M^{(e)}\right]=\left[M_{w}^{(e)}\right]+\left[M_{u}^{(e)}\right],}
\end{aligned}
$$$$
\left[M_{w}^{(e)}\right]=\left[\begin{array}{ccc}
{[0]} & {[0]} & {[0]} \\
{[0]} & {\left[M_{w w w}\right]} & {[0]} \\
{[0]} & {[0]} & {[0]}
\end{array}\right],
$$$$
\left[M_{u}^{(e)}\right]=\left[\begin{array}{lll}
{\left[M_{u u u}\right]} & {\left[M_{u u w}\right]} & {\left[M_{u u \beta}\right]} \\
{\left[M_{u u w}^{T}\right]} & {\left[M_{u w w}\right]} & {\left[M_{u w \beta}\right]} \\
{\left[M_{u u \beta}^{T}\right]} & {\left[M_{u w \beta}^{T}\right]} & {\left[M_{u \beta \beta}\right]}
\end{array}\right],
$$$$
\left[M_{w w w}\right]=B_{1} \int_{0}^{L_{e}}\left[N_{w}\right]^{T}\left[N_{w}\right] d x,
$$ 


$$
\begin{aligned}
& {\left[M_{\text {uuu }}\right]=B_{1} \int_{0}^{L_{e}}\left[N_{u}\right]^{T}\left[N_{u}\right] d x} \\
& {\left[M_{u u w}\right]=B_{2} \int_{0}^{L_{e}}\left[N_{w}^{\prime}\right]^{T}\left[N_{u}\right] d x} \\
& {\left[M_{u u \beta}\right]=B_{3} \int_{0}^{L_{e}}\left[N_{u}\right]^{T}\left[N_{u}\right] d x,} \\
& {\left[M_{u w w}\right]=B_{4} \int_{0}^{L_{e}}\left[N_{w}^{\prime}\right]^{T}\left[N_{w}^{\prime}\right] d x} \\
& {\left[M_{u w \beta}\right]=B_{5} \int_{0}^{L_{e}}\left[N_{w}^{\prime}\right]^{T}\left[N_{u}\right] d x} \\
& {\left[M_{u \beta \beta}\right]=B_{6} \int_{0}^{L_{e}}\left[N_{u}\right]^{T}\left[N_{u}\right] d x} \\
& B_{1}=\rho_{b} b h_{b}+\rho_{v} b h_{v}+\rho_{c} b h_{c}, \\
& B_{2}=-\rho_{b} b \int_{-h_{b} / 2}^{h_{b} / 2} z d z-\rho_{v} b \int_{h_{b} / 2}^{h_{b} / 2+h_{v}} z d z \\
& -\rho_{c} b \int_{h_{b} / 2+h_{v}}^{h-h_{b} / 2} z d z \\
& B_{3}=\rho_{v} b \int_{h_{b} / 2}^{h_{b} / 2+h_{v}}\left(\frac{h_{b}}{2}-z\right) d z \\
& +\rho_{c} b \int_{h_{b} / 2+h_{v}}^{h-h_{b} / 2}\left(k_{2} z^{2}+k_{1} z+k_{0}\right) d z \\
& B_{4}=\rho_{b} b \int_{-h_{b} / 2}^{h_{b} / 2} z^{2} d z+\rho_{v} b \int_{h_{b} / 2}^{h_{b} / 2+h_{v}} z^{2} d z \\
& +\rho_{c} b \int_{h_{b} / 2+h_{v}}^{h-h_{b} / 2} z^{2} d z \\
& B_{5}=\rho_{v} b \int_{h_{b} / 2}^{h_{b} / 2+h_{v}} z\left(z-\frac{h_{b}}{2}\right) d z \\
& -\rho_{c} b \int_{h_{b} / 2+h_{v}}^{h-h_{b} / 2} z\left(k_{2} z^{2}+k_{1} z+k_{0}\right) d z, \\
& B_{6}=\rho_{v} b \int_{h_{b} / 2}^{h_{b} / 2+h_{v}}\left(z-\frac{h_{b}}{2}\right)^{2} d z \\
& +\rho_{c} b \int_{h_{b} / 2+h_{v}}^{h-h_{b} / 2}\left(k_{2} z^{2}+k_{1} z+k_{0}\right)^{2} d z .
\end{aligned}
$$

\section{Conflict of Interests}

The authors declare that there is no conflict of interests regarding the publication of this paper.

\section{Acknowledgment}

This work is supported by the National Natural Science Foundation of China under Grant no. 11302222.

\section{References}

[1] A. D. Nashif, D. I. Jones, and J. P. Henderson, Vibration Damping, John Wiley \& Sons, New York, NY, USA, 1985.

[2] C. D. Johnson, "Design of passive damping systems," Journal of Mechanical Design, vol. 117, pp. 171-176, 1995.

[3] G. R. Tomlinson, "The use of constrained layer damping in vibration control," International Journal of Mechanical Sciences, vol. 32, no. 3, pp. 233-242, 1990.

[4] R. Fan, G. Meng, J. Yang, and C. He, "Experimental study of the effect of viscoelastic damping materials on noise and vibration reduction within railway vehicles," Journal of Sound and Vibration, vol. 319, no. 1-2, pp. 58-76, 2009.

[5] M. D. Rao, "Recent applications of viscoelastic damping for noise control in automobiles and commercial airplanes," Journal of Sound and Vibration, vol. 262, no. 3, pp. 457-474, 2003.

[6] B. C. Nakra, "Vibration control in machines and structures using viscoelastic damping," Journal of Sound and Vibration, vol. 211, no. 3, pp. 449-465, 1998.

[7] S. C. Huang, D. J. Inman, and E. M. Austin, "Some design considerations for active and passive constrained layer damping treatments," Smart Materials and Structures, vol. 5, no. 3, pp. 301-313, 1996.

[8] E. Carrera and S. Brischetto, "A survey with numerical assessment of classical and refined theories for the analysis of sandwich plates," Applied Mechanics Reviews, vol. 62, no. 1, pp. $1-17,2009$.

[9] E. Reissner, "The effect of transverse shear deformation on the bending of elastic plates," Journal of Applied Mechanics, vol. 12, no. 1, pp. 69-77, 1945.

[10] E. Reissner and Y. Stavsky, "Bending and stretching of certain types of heterogeneous aeolotropic elastic plates," Journal of Applied Mechanics, vol. 28, no. 3, pp. 402-408, 1961.

[11] J. N. Reddy, "A simple higher-order theory for laminated composite plates," Journal of Applied Mechanics-Transactions ASME, vol. 51, no. 4, pp. 745-752, 1984.

[12] C. M. A. Vasques, B. R. Mace, P. Gardonio, and J. D. Rodrigues, "Arbitrary active constrained layer damping treatments on beams: finite element modelling and experimental validation," Computers \& Structures, vol. 84, no. 22-23, pp. 1384-1401, 2006.

[13] R. A. S. Moreira and J. D. Rodrigues, "A layerwise model for thin soft core sandwich plates," Computers \& Structures, vol. 84, no. 19-20, pp. 1256-1263, 2006.

[14] E. Carrera, "Historical review of Zig-Zag theories for multilayered plates and shells," Applied Mechanics Reviews, vol. 56, no. 3, pp. 287-308, 2003.

[15] X. Wang and G. Shi, "A simple and accurate sandwich plate theory accounting for transverse normal strain and interfacial stress continuity," Composite Structures, vol. 107, pp. 620-628, 2014.

[16] F. G. Flores, "Implementation of the refined zigzag theory in shell elements with large displacements and rotations," Composite Structures, vol. 118, pp. 560-570, 2014.

[17] D. Versino, M. Gherlone, and M. Di Sciuva, "Four-node shell element for doubly curved multilayered composites based on 
the refined zigzag theory," Composite Structures, vol. 118, no. 1, pp. 392-402, 2014.

[18] M. Aydogdu, "A new shear deformation theory for laminated composite plates," Composite Structures, vol. 89, no. 1, pp. 94101, 2009.

[19] W. Zhen and C. Wanji, "A global-local higher order theory including interlaminar stress continuity and $\mathrm{C}^{0}$ plate bending element for cross-ply laminated composite plates," Computational Mechanics, vol. 45, no. 5, pp. 387-400, 2010.

[20] E. M. Kerwin, "Damping of flexural waves by a constrained viscoelastic layer," The Journal of the Acoustical Society of America, vol. 31, no. 7, pp. 952-692, 1959.

[21] D. Ross, E. Ungar, and J. E. Kerwin, "Damping of flexural vibrations by means of viscoelastic laminates," in Structural Damping, ASME, New York, NY, USA, 1959.

[22] D. J. Mead and S. Markus, "The forced vibration of a three-layer, damped sandwich beam with arbitrary boundary conditions," Journal of Sound and Vibration, vol. 10, no. 2, pp. 163-175, 1969.

[23] D. K. Rao, "Frequency and loss factors of sandwich beams under various boundary conditions," Journal of Mechanical Engineering Science, vol. 20, no. 5, pp. 271-282, 1978.

[24] P. K. Roy and N. Ganesan, "Vibration and damping analysis of circular plates with constrained damping layer treatment," Computers \& Structures, vol. 49, no. 2, pp. 269-274, 1993.

[25] H. Zheng, C. Cai, and X. M. Tan, "Optimization of partial constrained layer damping treatment for vibrational energy minimization of vibrating beams," Computers \& Structures, vol. 82, no. 29-30, pp. 2493-2507, 2004.

[26] H. Zheng, G. S. H. Pau, and Y. Y. Wang, "A comparative study on optimization of constrained layer damping treatment for structural vibration control," Thin-Walled Structures, vol. 44, no. 8, pp. 886-896, 2006.

[27] B. Khalfi and A. Ross, "Transient response of a plate with partial constrained viscoelastic layer damping," International Journal of Mechanical Sciences, vol. 68, pp. 304-312, 2013.

[28] N. Kumar and S. P. Singh, "Vibration and damping characteristics of beams with active constrained layer treatments under parametric variations," Materials \& Design, vol. 30, no. 10, pp. 4162-4174, 2009.

[29] M. Hamdaoui, G. Robin, M. Jrad, and E. M. Daya, "Optimal design of frequency dependent three-layered rectangular composite beams for low mass and high damping," Composite Structures, vol. 120, pp. 174-182, 2015.

[30] G. A. Lesieutre and U. Lee, "A finite element for beams having segmented active constrained layers with frequency-dependent viscoelastics," Smart Materials and Structures, vol. 5, no. 5, pp. 615-627, 1996.

[31] E. Barbieri, A. Cammarano, S. De Rosa, and F. Franco, "Waveguides of a composite plate by using the spectral finite element approach," Journal of Vibration and Control, vol. 15, no. 3, pp. 347-367, 2009.

[32] G. Solaroli, Z. Gu, A. Baz, and M. Ruzzene, "Wave propagation in periodic stiffened shells: spectral finite element modeling and experiments," Journal of Vibration and Control, vol. 9, no. 9, pp. 1057-1081, 2003.

[33] B. R. Mace, D. Duhamel, M. J. Brennan, and L. Hinke, "Finite element prediction of wave motion in structural waveguides," The Journal of the Acoustical Society of America, vol. 117, no. 5, pp. 2835-2843, 2005.

[34] P. J. Shorter, "Wave propagation and damping in linear viscoelastic laminates," The Journal of the Acoustical Society of America, vol. 115, no. 5, pp. 1917-1925, 2004.
[35] H. Hu, S. Belouettar, M. Potier-Ferry, and E. M. Daya, "Review and assessment of various theories for modeling sandwich composites," Composite Structures, vol. 84, no. 3, pp. 282-292, 2008.

[36] A. Plouin and E. Balmes, "A test validated model of plates with constrained viscoelastic materials," in Proceedings of the International Modal Analysis Conference, pp. 194-200, Kissimmee, Fla, USA, February 1999.

[37] R. Moreira and J. D. Rodrigues, "Constrained damping layer treatments: finite element modeling," Journal of Vibration and Control, vol. 10, no. 4, pp. 575-595, 2004.

[38] C. D. Johnson and D. A. Kienholz, "Finite element prediction of damping in structures with constrained viscoelastic layers," AIAA Journal, vol. 20, no. 9, pp. 1284-1290, 1982.

[39] S. H. Zhang and H. L. Chen, "A study on the damping characteristics of laminated composites with integral viscoelastic layers," Composite Structures, vol. 74, no. 1, pp. 63-69, 2006.

[40] H. Koruk and K. Y. Sanliturk, "Optimisation of damping treatments based on big bang-big crunch and modal strain energy methods," Journal of Sound and Vibration, vol. 333, no. 5, pp. 1319-1330, 2014.

[41] R. Plunkett and C. T. Lee, "Length optimization for constrained viscoelastic layer damping," The Journal of the Acoustical Society of America, vol. 48, no. 1, pp. 150-161, 1970.

[42] P. Trompette and J. Fatemi, "Damping of beams. Optimal distribution of cuts in the viscoelastic constrained layer," Structural Optimization, vol. 13, no. 2-3, pp. 167-171, 1997.

[43] M. A. Al-Ajmi and R. I. Bourisli, "Optimum design of segmented passive-constrained layer damping treatment through genetic algorithms," Mechanics of Advanced Materials and Structures, vol. 15, no. 3-4, pp. 250-257, 2008.

[44] G. Lepoittevin and G. Kress, "Optimization of segmented constrained layer damping with mathematical programming using strain energy analysis and modal data," Materials \& Design, vol. 31, no. 1, pp. 14-24, 2010.

[45] P. P. Hujare, A. D. Sahasrabudhe, and S. D. Chinchawade, "Experimental and numerical analysis of the effect of segmentation on modal loss factor of constrained layer damped beam," in Proceedings of the ASME 2014 International Design Engineering Technical Conferences and Computers and Information in Engineering Conference, vol. 8, pp. 17-20, Buffalo, NY, USA, August 2014.

[46] A. Kadam and P. Hujare, "Optimization of segmented constrained layer damping literature review," International Journal of Engineering and Advanced Technology, vol. 3, no. 5, pp. 151153, 2014.

[47] R. K. Kapadia and G. Kawiecki, "Experimental evaluation of segmented active constrained layer damping treatments," Journal of Intelligent Material Systems and Structures, vol. 8, no. 2, pp. 103-111, 1997.

[48] M. A. Trindade, A. Benjeddou, and R. Ohayon, "Modeling of frequency-dependent viscoelastic materials for active-passive vibration damping," Journal of Vibration and Acoustics, vol. 122, no. 2, pp. 169-174, 1999.

[49] Y. Liu and K. W. Wang, "Distribution of active and passive constraining sections for hybrid constrained layer damping treatments," Journal of Intelligent Material Systems and Structures, vol. 13, no. 1, pp. 23-34, 2002.

[50] R. F. Kristensen, K. L. Nielsen, and L. P. Mikkelsen, "Numerical studies of shear damped composite beams using a constrained damping layer," Composite Structures, vol. 83, no. 3, pp. 304-311, 2008 . 
[51] B. R. Sher and R. A. S. Moreira, "Dimensionless analysis of constrained damping treatments," Composite Structures, vol. 99, pp. 241-254, 2013.

[52] Y. S. Shin and G. J. Maurer, "Vibration response of constrained viscoelastically damped plates: analysis and experiments," Finite Elements in Analysis and Design, vol. 7, no. 4, pp. 291-297, 1991. 


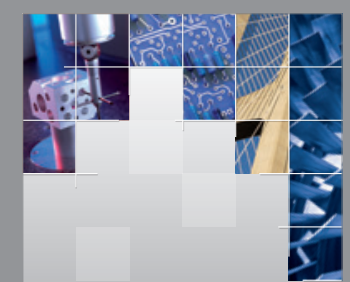

\section{Enfincering}
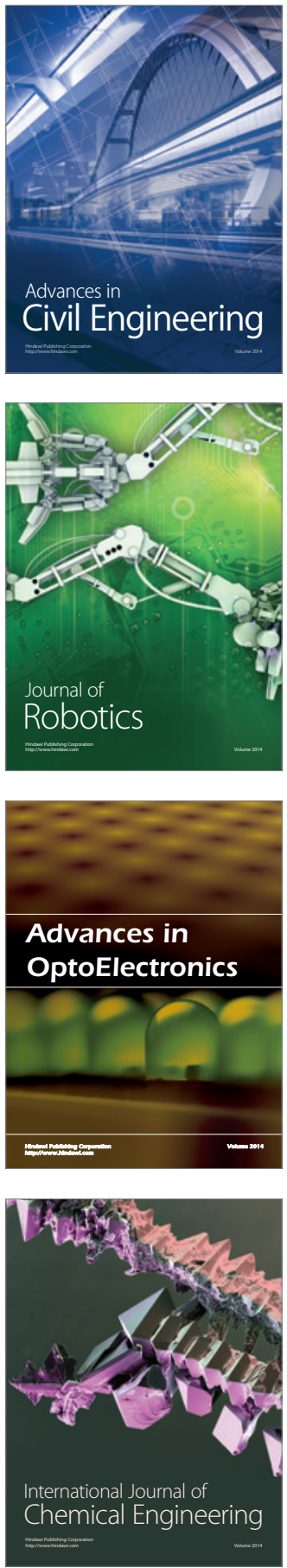

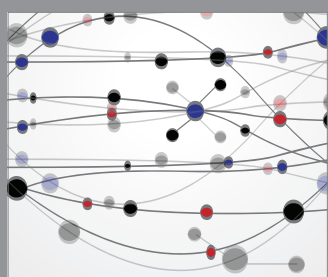

The Scientific World Journal

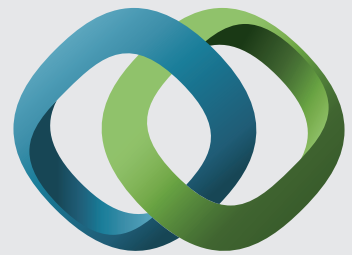

\section{Hindawi}

Submit your manuscripts at

http://www.hindawi.com
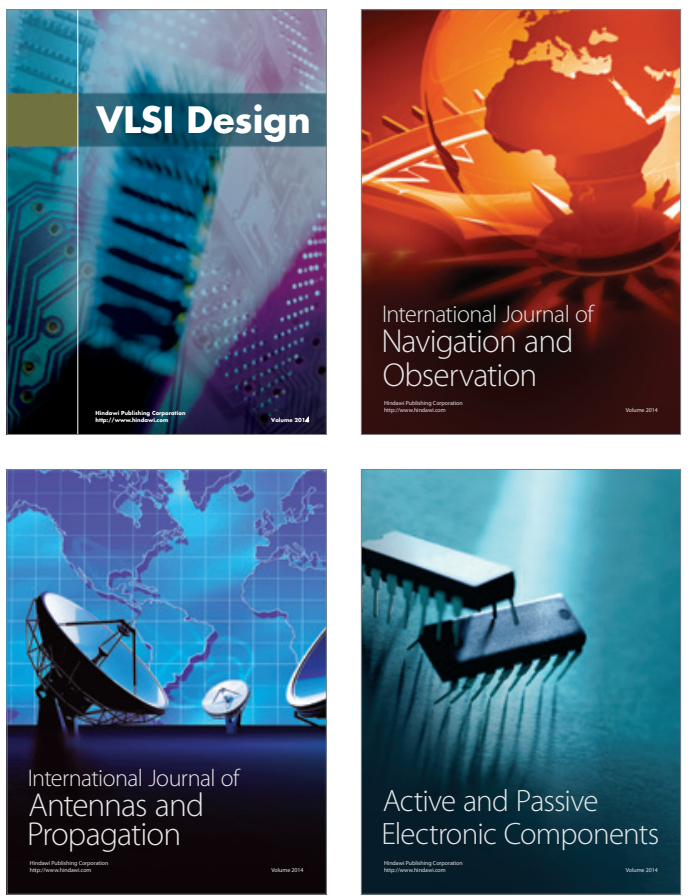
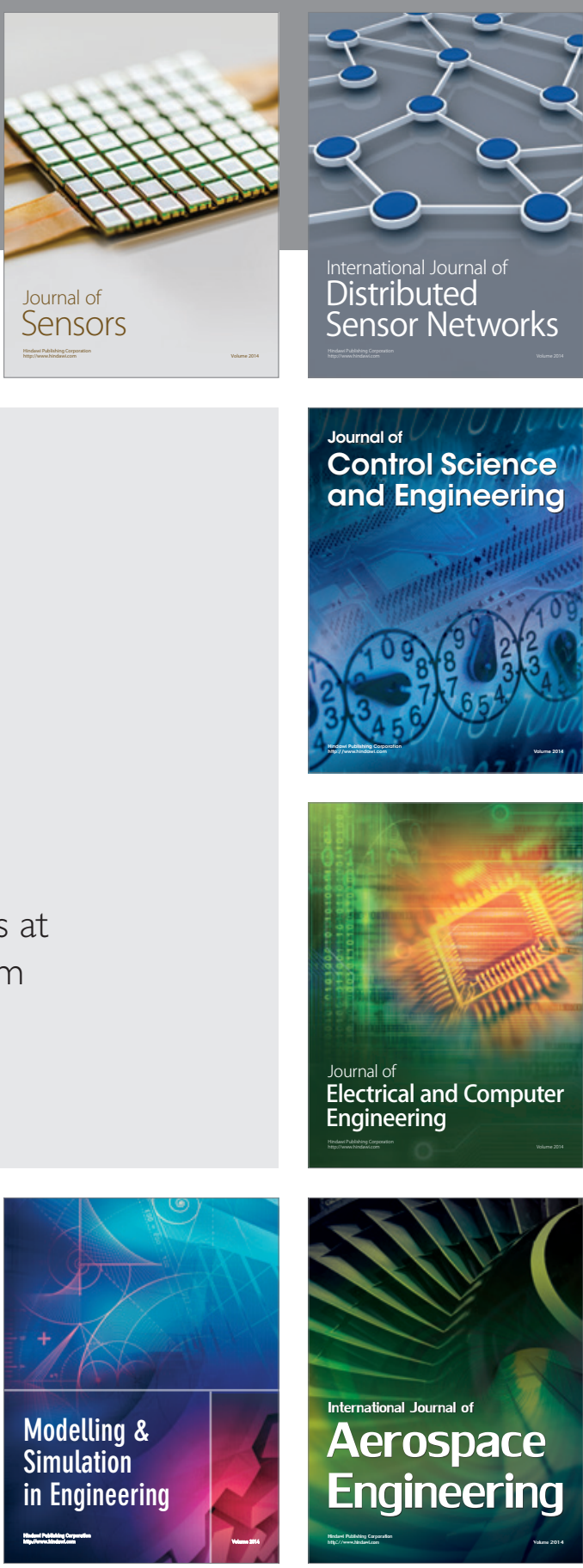

International Journal of

Distributed

Sensor Networks

Journal of

Control Science

and Engineering
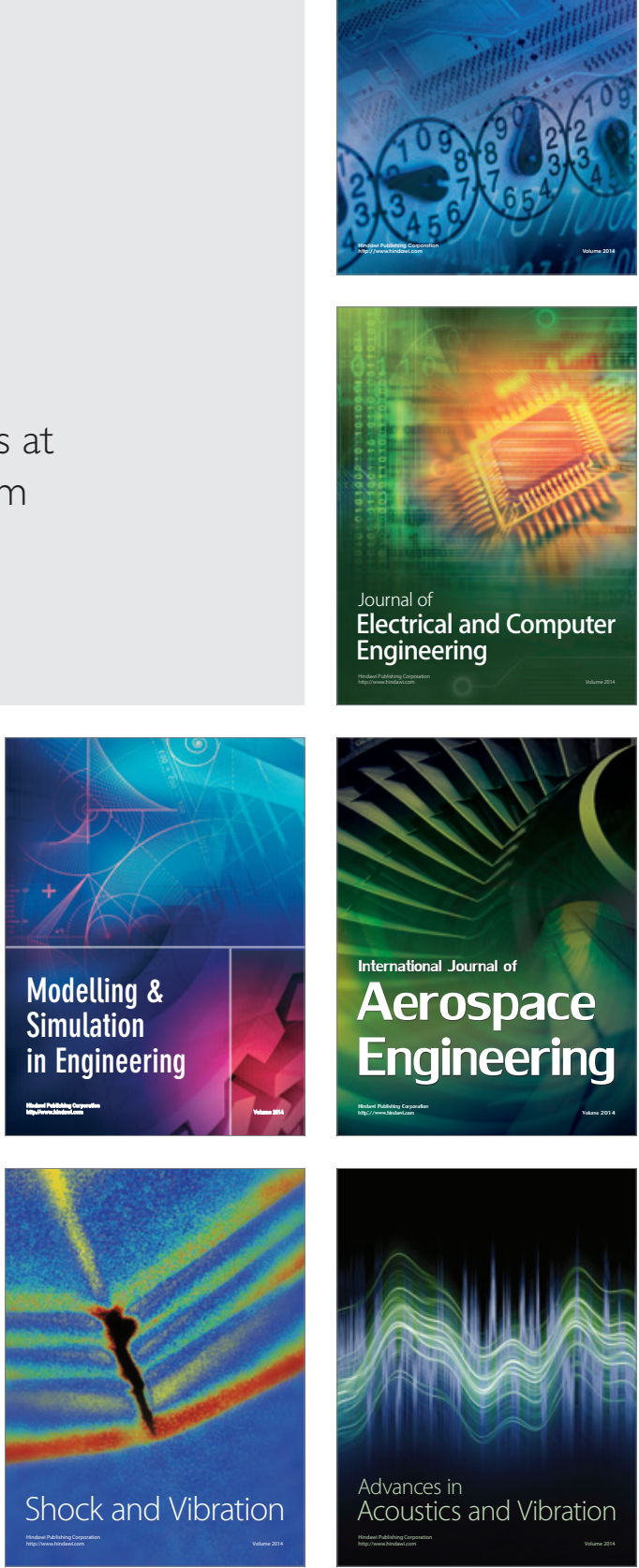